\title{
Corrosion at the carbon steel-clay borehole water interface under anoxic alkaline and fluctuating temperature conditions
}

\author{
Michel L. Schlegel ${ }^{\mathrm{a}, \mathrm{b}, *}$, Sophia Necib ${ }^{\mathrm{c}}$, Sylvie Daumas ${ }^{\mathrm{d}}$, Marc Labat ${ }^{\mathrm{e}}$, Cécile Blanc ${ }^{\mathrm{a}}$, Eddy Foy ${ }^{\mathrm{f}}$, \\ Yannick Linard ${ }^{\mathrm{c}}$ \\ a DEN - Service d'Etudes Analytiques et de Réactivité des Surfaces (SEARS), CEA, Université Paris-Saclay, F-91191, Gif sur Yvette, France \\ ${ }^{\mathrm{b}}$ University of Evry-Val d'Essonne, LAMBE, F-91025 Evry, France \\ c ANDRA, Meuse-Haute Marne Research Center, DRD/SCM, RD 960, 55290 Bure, France \\ ${ }^{\mathrm{d}}$ CFG Services, 117 Avenue de Luminy, 13009 Marseille, France \\ e IRD-MIO, Aix-Marseille Université, Université du Sud Toulon-Var, CNRS/INSU, IRD, MIO UM110,163 avenue de Luminy, Case 925, F-13288 Marseille cedex 9, France \\ ${ }^{\mathrm{f}}$ CEA, DSM, IRaMIS/NIMBE/LAPA, Bât. 637, 91191 Gif-sur-Yvette, France
}

\section{A R T I C L E I N F O}

\section{Keywords:}

Carbon steel

Clay

Anoxic

Nuclear waste repository

Fe-silicate

Sulfide

\begin{abstract}
A B S T R A C T
Coupons of carbon steel were corroded in situ in anoxic clay porewater under slightly alkaline conditions. Sample damage was less than $1 \mu \mathrm{m}$ for 9 months at $85^{\circ} \mathrm{C}$ only, and corrosion interfaces were covered by a thin, protective layer of Fe-silicate. The damage was more significant for samples exposed to room temperature transients (up to $38 \mu \mathrm{m}$ for two years), and the long-term surface differentiated in cathodic (Fe-silicate covered) areas and anodic crevices filled with siderite, chukanovite, $\beta-\mathrm{Fe}_{2}(\mathrm{OH})_{3} \mathrm{Cl}$, and covered by tubercles. Sulfide compounds were detected, and were related to the metabolism of sulfate-reducing prokaryotes detected by microbiological techniques.
\end{abstract}

\section{Introduction}

High-level nuclear waste (HLW) is a legacy of the use of nuclear power for peaceful or military purposes, and must now be properly disposed of to shield the future generations from its harmful effects. Over the years, consensus has emerged to consider disposal in deep underground repositories as the safest solution [1-3]. For example, the French project called CIGEO (for "Centre Industriel de stockage GEOlogique") has been articulated along the setup of several engineering and natural barriers, mitigating the migration and transfer of radionuclides at the Earth surface. Thus, HLW as a nuclear glass cooled in stainless steel containers would be encapsulated in low-alloy carbon steel (C-steel) overpacks and introduced in C-steel casings within horizontal microtunnels drilled in the Callovo-Oxfordian (COx) clay of the Paris Basin [4,5]. The casing would allow the nuclear waste to be retrieved from the repository, should new technologies of nuclear waste handling be developed in the future. In 2005, the design involved the presence of voids between the overpack and the casing and between the casing and the clay formation. These voids were to be gradually refilled by porewater seeping from the clay formation, leading to corrosion of casings and overpacks in successively distinct environments (i.e. in contact with clay, porewater, or vapour phase at equilibrium with porewater). Under such conditions, general corrosion is expected to predominate over long term for C-steel [6-10], however, pitting could not be entirely ruled out, even though pits would remain metastable and tend to close up [7]. Hence considerations on the long-term integrity of the HLW disposal have motivated a dedicated research effort on the corrosion of C-steel under repository conditions.

Important insight into the long-term behaviour of C-steels in rock environments has been obtained from the research work led by the oil and gas industry [11,12]. This knowledge has been complemented by several specific studies devoted to understand the synergy between steel corrosion and matrix alteration in clay or clay materials [13-33]. The results of these studies have been fed into models based on a geochemical approach to improve the long-term understanding of these corrosion systems [34-39]. As a complementary approach, characterization of archaeological artifacts have been implemented to identify corrosion mechanisms and products of likely preponderance over timescales inaccessible to laboratory experiments or modern industry (e.g. [40-50]). To consolidate this body of knowledge, the French Agency for the Management of Nuclear Waste (Andra) has designed an in situ experiment in the COx claystone. In this experiment, C-steel coupons were in contact at $85^{\circ} \mathrm{C}$ with water seeping from clay in a test chamber under monitored and nominally reducing physico-chemical

\footnotetext{
* Corresponding author at: DEN - Service d'Etudes Analytiques et de Réactivité des Surfaces (SEARS), CEA, Université Paris-Saclay, F-91191, Gif sur Yvette, France.

E-mail address: Michel.Schlegel@cea.fr (M.L. Schlegel).
} 
Table 1

List of rods investigated in this study.

\begin{tabular}{lll}
\hline Rod & Introduction time (days) & Removal time (days) \\
\hline Series 2-Rod 1 & $\mathrm{t}_{0}+643$ & $\mathrm{t}_{0}+748$ \\
Series 2-Rod 2 & $\mathrm{t}_{0}+643$ & $\mathrm{t}_{0}+643$ \\
Series 2-Rod 3 & $\mathrm{t}_{0}+643$ & $\mathrm{t}_{0}+643$ \\
Series 3-Rod 1 & $\mathrm{t}_{0}+1035$ & $\mathrm{t}_{0}+1169$ \\
Series 3-Rod 2 & $\mathrm{t}_{0}+1035$ & $\mathrm{t}_{0}+13143$ \\
Series 3-Rod 3 & $\mathrm{t}_{0}+1035$ & $\mathrm{t}_{0}+1783$ \\
Series 3-Rod 4 & $\mathrm{t}_{0}+1035$ & $\mathrm{t}_{0}+1783$ \\
\end{tabular}

conditions ( $\mathrm{pH}$, Eh, water and gas composition). Periodically, sets of coupons were retrieved for gravimetric assessment of corrosion rates, and, for some of them, replaced by new sets. Analysis of the borehole water revealed the occurrence of a $\mathrm{pH}$ transient attributed to oxidation of the COx claystone after borehole drilling and before installation of the test chamber [51]. These acidic conditions were invoked to explain high rates of corrosion (up to $200 \mu \mathrm{m} / \mathrm{a}$ ) observed for coupons initially present in the test chamber [51,52]. The present study focuses on coupons introduced in the test chamber after the acidic transient, when the $\mathrm{pH}$ was back to basic values. Macroscopic measurements and microscopic characterizations were performed to unravel the relationship between corrosion rates and the nature of Corrosion Products (CPs).

\section{Material and methods}

\subsection{Nature of C-steel samples}

Corrosion experiments were performed on coupons $\left(23 \times 16 \times 2 \mathrm{~mm}^{3}\right)$ of A37, SA516 and P235 grade C-steel, and from a P235 welded zone (P235s; the weld zone being in the middle of the coupon) [51]. Metallurgical analysis showed that coupons of plain Csteel exhibit a ferrite-pearlite microstructure with pearlite bands either parallel or perpendicular to the smallest surface, and ferrite grains of about $20-30 \mu \mathrm{m}$. The welded zone of the P235s sample displayed a martensitic microstructure with grain diameters up to $300 \mu \mathrm{m}$. These coupons were positioned on a rod-shaped, PEEK-made sample holder.

\subsection{Experimental setup and physico-chemical monitoring}

The "MCO" (for "Materials Corrosion") experimental setup has been described elsewhere [51]. Briefly, in situ corrosion was performed in a test chamber at the bottom of a vertical descending borehole in the COx claystone of the French Underground Laboratory (Bure). The test chamber was initially half-filled with a synthetic clay porewater which was gradually replaced by water seeping from the clay formation during the experiment. The test chamber was connected to cabinets located in the gallery of the laboratory by a series of stainless steel (SS) lines for heating of the test chamber, on-line monitoring, and periodic sampling of the fluids. Temperature, $\mathrm{pH}$, oxidoreduction potential (Eh), conductivity (Ec) and gas/liquid flowrates were continuously monitored by appropriate sensors. The total pressure was also monitored in situ by a sensor located at the bottom of the test chamber.

Periodically, borehole water and gas were sampled in 316 SS gastight vials for analysis of $\mathrm{pH}$, alkalinity, and composition. The concentration of dissolved $\mathrm{Li}^{+}\left([\mathrm{Li}]_{\mathrm{aq}}\right), \mathrm{Na}^{+}\left([\mathrm{Na}]_{\mathrm{aq}}\right), \mathrm{K}^{+}\left([\mathrm{Mg}]_{\mathrm{aq}}\right), \mathrm{Mg}^{2+}$ $\left([\mathrm{Mg}]_{\mathrm{aq}}\right)$ and $\mathrm{Ca}^{2+}\left([\mathrm{Ca}]_{\mathrm{aq}}\right)$ were analysed by a Dionex ion chromatograph using an IonPac CG $12 \mathrm{~A}, 4 \times 50 \mathrm{~mm}$ guard column and a CS $12 \mathrm{~A}, 4 \times 250 \mathrm{~mm}$ analytical column. The concentrations of dissolved $\mathrm{Cl}^{-}\left([\mathrm{Cl}]_{\mathrm{aq}}\right), \mathrm{SO}_{4}{ }^{2-}\left(\left[\mathrm{SO}_{4}\right]_{\mathrm{aq}}\right), \mathrm{S}_{2} \mathrm{O}_{3}{ }^{2-}$ and acetate were analysed by a Dionex ion chromatograph ICS 1500 using an IonPac AG 22, $4 \times 50 \mathrm{~mm}$ guard column and a AS $22,4 \times 250 \mathrm{~mm}$ analytical column. $\mathrm{NH}_{4}{ }^{+}$and total sulfide $\left(\mathrm{H}_{2} \mathrm{~S}, \mathrm{~S}^{2-}, \mathrm{HS}^{-}\right)$were analysed photometrically. Dissolved $\mathrm{Si}\left([\mathrm{Si}]_{\mathrm{aq}}\right), \mathrm{Cr}$, and $\mathrm{Fe}\left([\mathrm{Fe}]_{\mathrm{aq}}\right)$ were analysed by inductively coupled plasma mass spectrometry. The composition of the gas samples was determined using a Shimadzu GC17A gas chromatograph equipped with two capillary columns. A Swagelock system allowed a rapid and direct connection of the sample cells with the evacuated inlet system of the gas chromatograph (8 Port Dual External Sample Injector, Valco Europe) without contact with atmosphere.

\subsection{Corrosion experiment}

For the corrosion experiments, coupons-carrying rods were inserted in the test chamber. The samples from the rod lower level were bathed by the seeping porewater. An initial set of seven rods ('Series 1') was introduced at $t_{0}$, and kept at ambient temperature for 77 days. The borehole temperature was then ramped up to a plateau of $85^{\circ} \mathrm{C}$ (attained at $t_{0}+193$ days). Rods were recovered after various reaction times. Some of the empty slots were then filled with new rods, first at $\mathrm{t}_{2}=\mathrm{t}_{0}+643$ days ("Series 2") and then at $\mathrm{t}_{3}=\mathrm{t}_{0}+1035$ days ("Series 3 "). The coupons investigated in this article are from "Series 2 " and "Series 3" rods (Table 1). Two heating failures occurred from $t_{0}+709$ to $t_{0}+792$ days, and again from $t_{0}+1432$ to $t_{0}+1539$ days. Rods "Series 3-Rod 1" and "Series 3 -Rod 2 " were reacted at $85^{\circ} \mathrm{C}$ only, whereas the other rods were also partially corroded at $25^{\circ} \mathrm{C}$.

Recovered rods were disassembled in a glove box. Some C-steel coupons were swabbed for microbial analysis, and then all coupons were rinsed with ethanol and dried to prevent post-oxidation. Some coupons were heat-sealed in aluminium bags and shipped for microstructural characterization [51]. Gravimetric measurements were performed on the remaining coupons as previously detailed [51]. From these measurements, the damaged thickness $e_{\text {cor }}$ (in $\mu \mathrm{m}$ ), was calculated according to

$\mathrm{e}_{\mathrm{cor}}=\frac{\Delta m}{S . \rho_{F e}}$

where $S$ is the surface area, $\Delta \mathrm{m}$ is the weight loss, and $\rho_{\mathrm{Fe}}$ is the iron density $\left(7.87 \mathrm{~g} \mathrm{~cm}^{-3}\right)$. The time-averaged corrosion rate $r$ is then calculated as

$r=\frac{e_{c o r}}{t}$,

where $t$ is the full reaction time. Thus temporal fluctuations in corrosion rates are smoothed out.

\subsection{Microbial analysis}

For microbiological characterisation, coupons (essentially SA516 grade) taken from the sample holder were immediately swabbed and the swabs inserted into tubes containing a sterile, anaerobic solution under non-growth conditions (neutral $\mathrm{pH}$, saline conditions with a reducing agent). Prior to characterization, the swabs were ultrasonically treated to re-suspend and disperse microorganisms. Microbial analyses were also performed on borehole water samples.

Total cell counting was performed by epifluorescence microscopy using the SYBR green marker and an Olympus BH-2 microscope with computer-controlled Lhesa 4036 camera. About 40 frames per sample were taken, and processed using the Labview-based Micromar software. 
For enumerations using the Most Probable Number (MPN) method [53], microbial suspensions were distributed and diluted in distinct media and incubated for seven weeks at temperatures of 30 and $60{ }^{\circ} \mathrm{C}$ for mesophilic and thermophilic prokaryotes, respectively. Positive reactions were seen via turbidity, microscopic validation, acidification, or darkening of the culture medium. The investigation focused on anaerobic fermenting prokaryotes, strict aerobic prokaryotes, sulfate-reducing prokaryotes (SRP) and thiosulfate-reducing prokaryotes (ThRP) present per $\mathrm{ml}$ of solution or per $\mathrm{cm}^{2}$ of the coupon surface.

Prokaryote viability was assessed by flux cytometry (CytoFLEX, Beckman Coulter) using SYBR Green and propidium iodide to detect total and intact microorganisms, respectively. The method combines the fluorescence signal from individual cells with analysis of light diffusion at small angle and at $90^{\circ}$.

For phylogenetic analysis, DNA extraction was followed by $16 \mathrm{~s}$ rRNA amplification (V3 fragment) by Polymerase Chain Reaction (PCR). The quantification of the total prokaryote content was performed by quantitative PCR (qPCR) using UV-based DNA quantification (NanoQuant technique) and Fluorescence-based DNA quantification (Qubit technique). After extraction and amplification, the biodiversity was studied using two molecular fingerprinting methods, based on tracing the electrophoretic migration patterns of single-strand or double-strand DNA. In the Single Strand Conformation Polymorphism (SSCP) method, DNA was denatured as single strands and separated by capillary electrophoresis using an automatic sequencer. Each SSCP electrophoregram peak then corresponds to the contribution of at least one species and the peak area reveals the species relative abundance. In the Denaturing Gradient Gel Electrophoresis (DGGE) method, DNA double strands were separated on a polyacrylamide gel. The major and minor DGGE bands were later excised and amplified, then sequenced for phylogenetic assignment.

\subsection{Coupon preparation and microstructural characterization}

Coupons of P235 and P235s steel were used for microstructural characterization of sample surfaces and cross sections (Table 2). For cross sections, coupons were embedded in epoxy resin (Epofix, Struers), cut perpendicular to the smallest side, and polished to at final roughness of $1 \mu \mathrm{m}$ [52]. These operations were performed in a glove box under $\mathrm{N}_{2}$ atmosphere to minimize oxidation during preparation.

For optical imaging and micro-Raman ( $\mu$ Raman) spectroscopy $(\mu R S)$, cross-sections were kept in airtight boxes with a $1 \mathrm{~mm}$ thick glass window. The corrosion interfaces were imaged with a Zeiss Imager M2 m microscope equipped with a CCD camera. $\mu$ Raman spectra were recorded on a LabRam HR spectrometer equipped with an Olympus BX41 microscope and a $50 \times$ long-range objective. Lasers with wavelengths $\lambda_{0}$ of 532 or $785 \mathrm{~nm}$ were used as excitation sources and power outputs were kept at reasonably low values $\left(\sim 500 \mu \mathrm{W} / \mu \mathrm{m}^{2}\right)$ to limit thermal degradation.

Scanning electron microscopy (SEM) was performed using a Field Emission Gun (FEG) SEM apparatus (JEOL JSM7000-F) operated at $10 \mathrm{kV}$. Samples were brought to the microscope in an anoxic container, and all subsequent transfers were performed quickly (less than $1 \mathrm{~min}$ ) to minimize exposure to air. Surface images were collected in Secondary Electron (SE) mode. Cross-sections were coated with a thin carbon layer, and imaged in BackScattered Electron (BSE) mode with a beam current of $2 \mathrm{nA}$. The trace of the coupon original surface was identified as the line separating cementite-containing and cementitefree CPs. Energy-Dispersive X-ray (EDX) spectra were collected on Points of Interest (PI) using a silicon-drift detector (Bruker XFlash 5010) equipped with a thin beryllium window, then corrected and quantified [52]. Measured amounts are given in atomic percent (at.\%), and, in the text, they are rounded to two significant digits. Distribution maps of selected chemical elements were recorded by continuous scanning of the sample and cumulative recording of EDX signal on each pixel. Note that high electron densities (e.g., Fe-rich areas) may locally lead to higher X-ray backgrounds, thereby over-estimating the apparent concentration of light elements ( $\mathrm{Mg}, \mathrm{Al}, \mathrm{Si}, \mathrm{S}$ ) on the maps. Micro X-ray Diffraction $(\mu \mathrm{XRD})$ was performed in transmission mode on $100 \mu \mathrm{m}$ thin sections held on Kapton adhesive tapes and confined by a thin polyethylene screen. $\mathrm{X}$-rays from a rotating anode source (Mo K $\alpha$ radiation) were focused to $30 \times 50 \mu \mathrm{m}^{2}$ (vertical $\times$ horizontal) on the sample by a Xenocs ${ }^{\circledR}$ FOX 2D MO 25_25P diffraction optic. Diffraction patterns were collected with a 2D dimensional detector (GE Healthcare image plate) and circularly integrated with the FIT2D software [54].

\section{Results and interpretation}

\subsection{Physico-chemical evolution of the test chamber and the fluids}

\subsubsection{Temperature and pressure}

At the time of Series 2 introduction ( $t_{0}+643$ days), the temperature in the reaction chamber was stable and around $85^{\circ} \mathrm{C}$ (Fig. 1a). After the first breakdown of the heating system $\left(t_{0}+708\right.$ days), the temperature dropped to $25^{\circ} \mathrm{C}$. After repair of the heating system, the temperature was increased to $85^{\circ} \mathrm{C}$ within a day, and remained stable until $\mathrm{t}_{0}+1432$ days, the time of the second breakdown. Again the temperature decreased asymptotically to $25^{\circ} \mathrm{C}$ for 107 days. Temperature was then restored at $85^{\circ} \mathrm{C}\left(\mathrm{t}_{0}+1539\right.$ days $)$ until the end of the experiment.

The pressure in the test chamber was initially maintained at 3 bar, but the first heating breakdown caused a tightness loss, and a decrease in pressure down to slightly above 1 bar (Fig. 1b, PRE-01 sensor). The tightness of the reaction chamber could not be restored, and so the pressure remained slightly above 1 bar until the end of the experiment. The water level in the test chamber was maintained at a constant level by withdrawing water seeping from the host rock.

\subsubsection{Borehole water composition}

Ex situ chemical analyses recorded $\mathrm{pH}$ values of 7.36 at $\mathrm{t}_{2}=\mathrm{t}_{0}+643$ days, 7.24 at $\mathrm{t}_{0}+684$ days and 7.22 at $\mathrm{t}_{0}+847$ days (Fig. 2a). The measured $\mathrm{pH}$ then increased up to 9.36 at $\mathrm{t}_{0}+1030$ days. Interestingly, part of this increase occurred when the test chamber did not contain any coupon (between $t_{0}+923$ and $t_{0}+1035$ days). After introduction of Series $3\left(t_{3}=t_{0}+1035\right.$ days $)$, the $\mathrm{pH}$ then steadily decreased down to 7.96 at $t_{0}+1783$ days, corresponding to

Table 2

List of samples investigated at the microscopic level.

\begin{tabular}{|c|c|c|c|c|c|}
\hline Sample & Rod & Steel grade & Introduction time (days) & Removal time (days) & Reaction time ${ }^{\mathrm{a}}$ (days) \\
\hline A241 & Series 2-Rod 1 & P235 & $t_{0}+643$ & $t_{0}+748$ & 104 days \\
\hline A261 & Series 2-Rod 1 & P235s & $t_{0}+643$ & $t_{0}+643$ & 104 days \\
\hline A254 & Series 3-Rod 1 & P235 & $\mathrm{t}_{0}+1035$ & $t_{0}+1169$ & 134 days \\
\hline A274 & Series 3-Rod 1 & $\mathrm{P} 235 \mathrm{~s}$ & $t_{0}+1035$ & $t_{0}+1169$ & 134 days \\
\hline A257 & Series 3-Rod 2 & P235 & $\mathrm{t}_{0}+1035$ & $t_{0}+1314$ & 279 days \\
\hline A277 & Series 3-Rod 2 & P235s & $\mathrm{t}_{0}+1035$ & $t_{0}+1314$ & 279 days \\
\hline A213 & Series 3- Rod 4 & P235 & $\mathrm{t}_{0}+1035$ & $t_{0}+1783$ & 748 days \\
\hline A260 & Series 3-Rod 3 & P235 & $\mathrm{t}_{0}+1035$ & $t_{0}+1783$ & 748 days \\
\hline
\end{tabular}


a

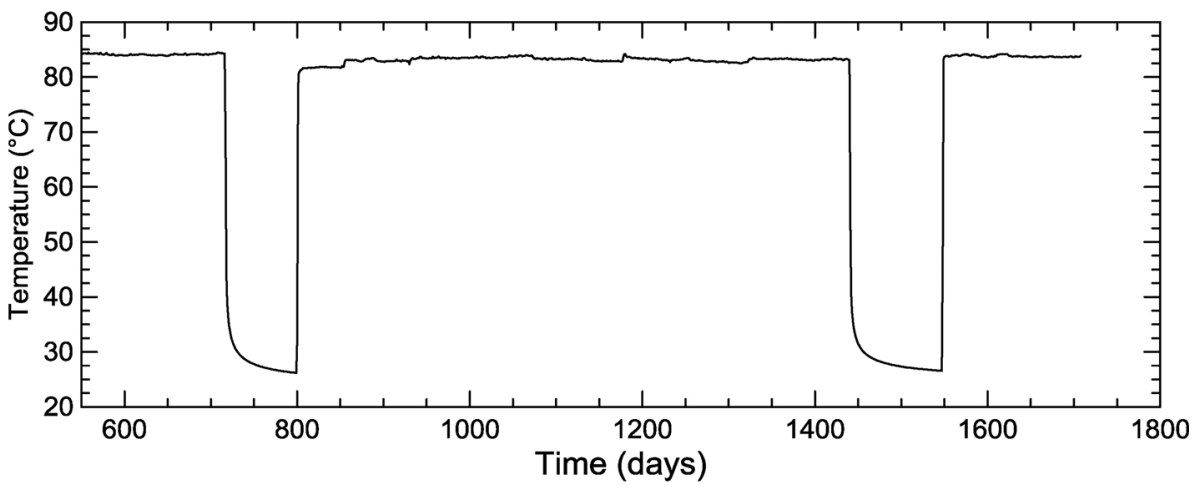

b

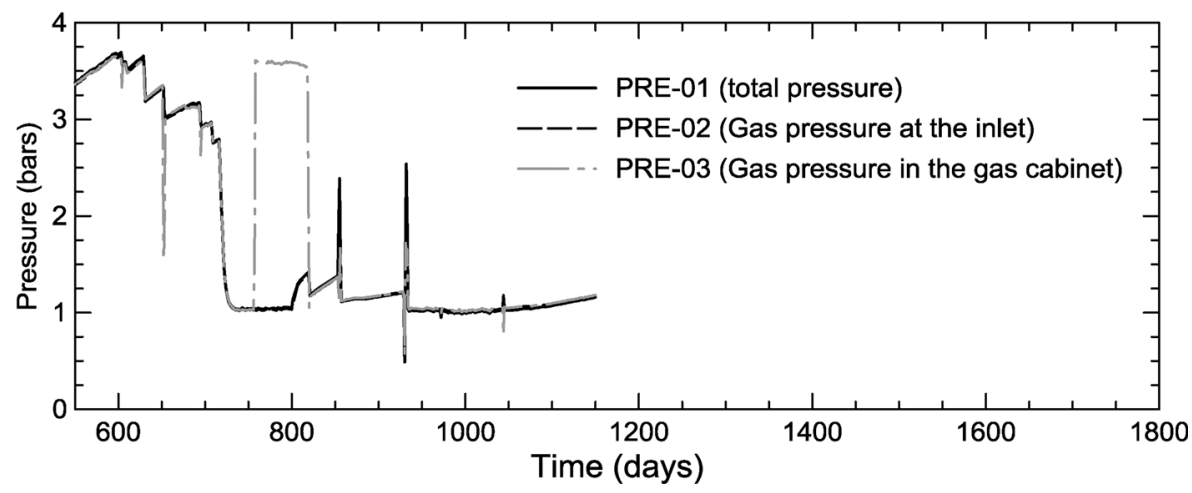

Fig. 1. Evolution of temperature (a) and pressure (b) in the test chamber.

withdrawal time for Series 3 rods.

At $t_{2}$, fully reducing conditions were established in the test chamber, as evident from the masured Eh value near $-100 \mathrm{mV}$ (data not shown). These reducing conditions likely resulted from C-steel corrosion and microorganism metabolism. At $\mathrm{t}_{0}+680$ days, the measured Eh suddenly increased up to $+500 \mathrm{mV} / \mathrm{SHE}$, due to residual $\mathrm{O}_{2}$ present in water sampling cells and diffusing to the Eh sensor. This residual $\mathrm{O}_{2}$ was promptly evacuated via the water outflow, and so never entered in the borehole. Hence, this measured high value was not representative of Eh in the test chamber. After the breakdown of the heating system at $t_{0}+709$ days and the resulting loss of gas tightness, the Eh readouts were considered no longer reliable.

Solution analysis after $t_{2}$ showed that $[\mathrm{Fe}]_{\text {aq }}$ was low, between 0.05 and $3 \mathrm{mg} / \mathrm{L}$, i.e. $10^{-6}$ and $5 \times 10^{-5} \mathrm{~mol} / \mathrm{L} \mathrm{(M)} \mathrm{(Fig.} \mathrm{2b).} \mathrm{Slight} \mathrm{in-}$ creases in $[\mathrm{Fe}]_{\text {aq }}$ were actually observed after $t_{2}$ and $t_{3}$, and may be related to $\mathrm{Fe}^{2+}$ release by C-steel corrosion for the Series 2 and Series 3 coupons, respectively. The decrease observed between $t_{0}+845$ days and $t_{3}$ coincides with the absence of C-steel in the test chamber, suggesting progressive dilution of dissolved Fe by the inflow of borehole water.

Anion analysis showed that $\left(\left[\mathrm{Cl}^{-}\right]_{\mathrm{aq}}\right)$ decreased gradually to $2030 \mathrm{mg} / \mathrm{L}\left(5.7 \times 10^{-2} \mathrm{M}\right)$ at $\mathrm{t}_{0}+848$ days, and then increased to $2520 \mathrm{mg} / \mathrm{L}\left(7.2 \times 10^{-2} \mathrm{M}\right)$ at $\mathrm{t}_{0}+1169$ days (Fig. $2 \mathrm{c}$ ). This is a possible consequence of the rising water level in the test chamber, enhancing leaching from the wall borehole and dissolution of salts precipitated during the drilling process. Indeed, $\left[\mathrm{SO}_{4}\right]_{\mathrm{aq}}$ values followed a similar trend, i.e. decrease to $1260 \mathrm{mg} / \mathrm{L}\left(1.3 \times 10^{-2} \mathrm{M}\right)$ at $\mathrm{t}_{0}+845$ days followed by an increase up to $1930 \mathrm{mg} / \mathrm{L}\left(2.1 \times 10^{-2} \mathrm{M}\right)$ at $\mathrm{t}_{0}+1040$ days. Both concentrations then decreased with longer reaction time, suggesting progressive dilution. The $\left[\mathrm{Na}^{+}\right]_{\mathrm{aq}}$ and $\left[\mathrm{K}^{+}\right]_{\mathrm{aq}}$ values also decreased to $t_{0}+848$ days, increased to $t_{0}+1169$ days, and then decreased again. This evolution is anticorrelated with that of $\left[\mathrm{Ca}^{2+}\right]_{\mathrm{aq}}$ and $\left[\mathrm{Mg}^{2+}\right]_{\mathrm{aq}}$, which attained minimal values of $0.8 \mathrm{mg} / \mathrm{L}$ $\left(2 \times 10^{-5} \mathrm{M}\right)$ and $3.5 \mathrm{mg} / \mathrm{L}\left(1.4 \times 10^{-4} \mathrm{M}\right)$, respectively, at $t_{0}+1314$ days (Fig. 2d). The concentration of dissolved organic carbon
(DOC) globally followed the same trend as the two anions (Fig. 2c), whereas Total Inorganic Carbon (TIC) fluctuated between 2.4 (reference value) and $80 \times 10^{-3} \mathrm{M}$. The higher TIC values coincided with the $\mathrm{pH}$ increase. Finally, $[\mathrm{Si}]_{\mathrm{aq}}$ decreased almost monotonously from $t_{0}+685$ to $t_{0}+1035$ days. It then increased to $6.5 \times 10^{-4} \mathrm{M}$ at $\mathrm{t}_{0}+1314$ days, and finally slightly drifted to lower values with reaction time.

\subsubsection{Gas phase composition}

Nitrogen remained the main gas in the test chamber, with a content between 91 and 97 vol.\%. Nitrogen was initially injected to reach an overpressure of 3 bar, allowing water outflow. After the breakdown of the heating system and the resulting partial loss in tightness, nitrogen was injected again to sample water, thereby altering the composition of the gas phase up to 1170 days. The second most important gas was $\mathrm{CO}_{2}$, with a partial gas fraction close to $2-3$ vol.\% before the breakdown, and increasing up to 6.6 vol.\% after restauration of heating (Fig. 3). This threefold increase actually corresponds to a constant $\mathrm{CO}_{2}$ partial pressure $\left(\mathrm{P}_{\mathrm{CO} 2}\right)$ of $\sim 0.066 \mathrm{bar}$, whatever the total pressure in the test chamber. This value is near the lower end of the range expected for deep clay aquifers at about $80^{\circ} \mathrm{C}$ [55]. The late decrease (about 3 vol.\% at $\mathrm{t}_{0}+1170$ days) coincided with the increase in $\mathrm{pH}$, and corresponds to redissolution of gaseous $\mathrm{CO}_{2}$. In contrast, the $\mathrm{H}_{2} \mathrm{~S}$ gas content significantly and steadily increases after $t_{0}+684$ days, a likely consequence of SRP metabolism. The $\mathrm{H}_{2}$ partial pressure remained always below 0.23 vol.\% despite evidence for extensive corrosion of the C-steel coupons. This is probably because $\mathrm{H}_{2}$ is highly volatile and can be easily lost in the geologic formation, or be reduced by microorganisms. Little oxygen $\left(\mathrm{O}_{2}\right)$ was detected $(<0.08$ vol.\%), confirming that the test chamber remained under (relatively) anoxic conditions. The little amount detected could explain some residual bioactivity from aerobic microorganisms. 

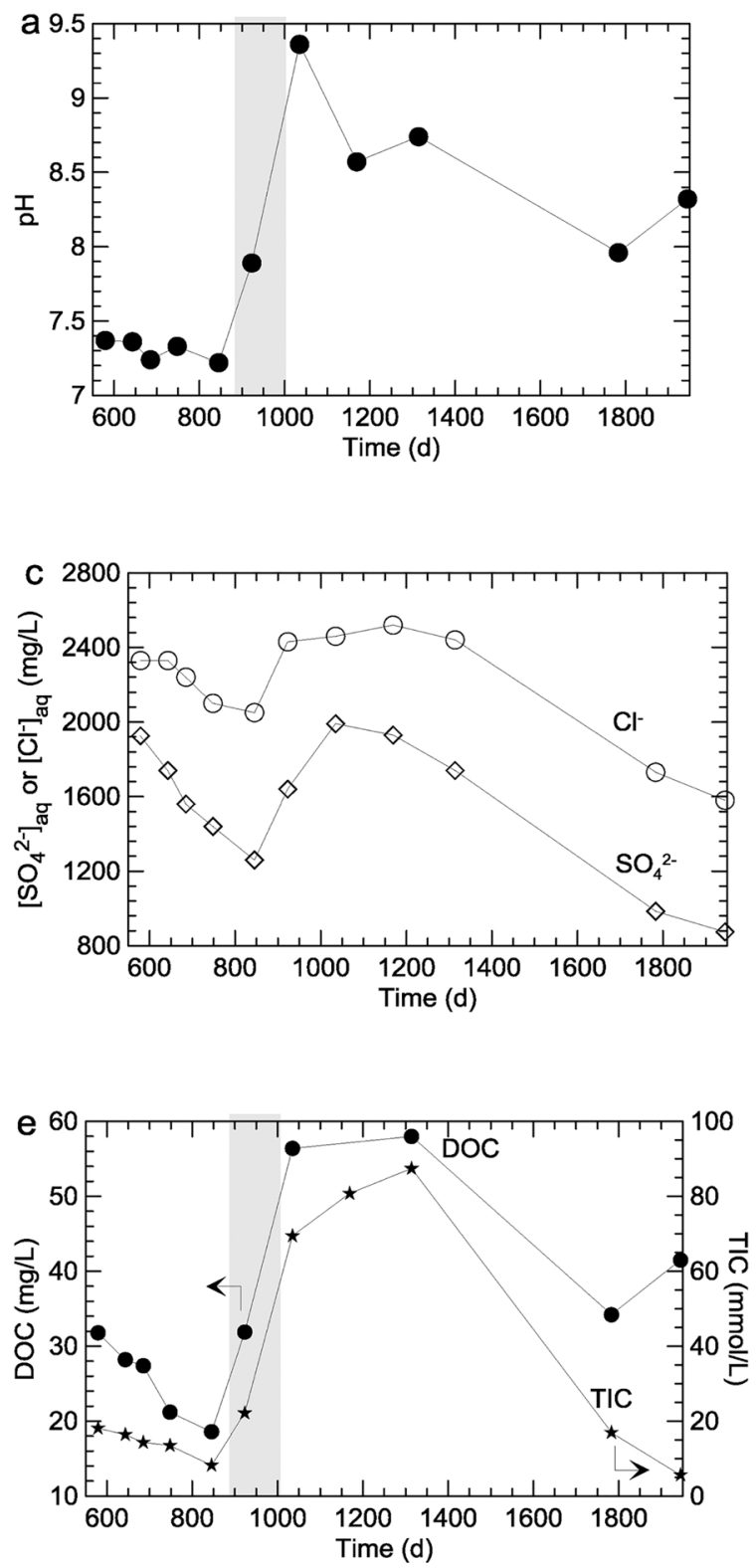

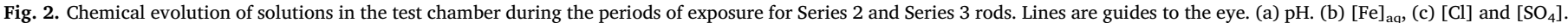
(d) $[\mathrm{Na}]_{\mathrm{aq}},[\mathrm{K}]_{\mathrm{aq}},[\mathrm{Ca}]_{\mathrm{aq}}$, and $[\mathrm{Mg}]_{\mathrm{aq}}$. (e) DOC and TIC. (f) $[\mathrm{Si}]_{\mathrm{aq}}$.

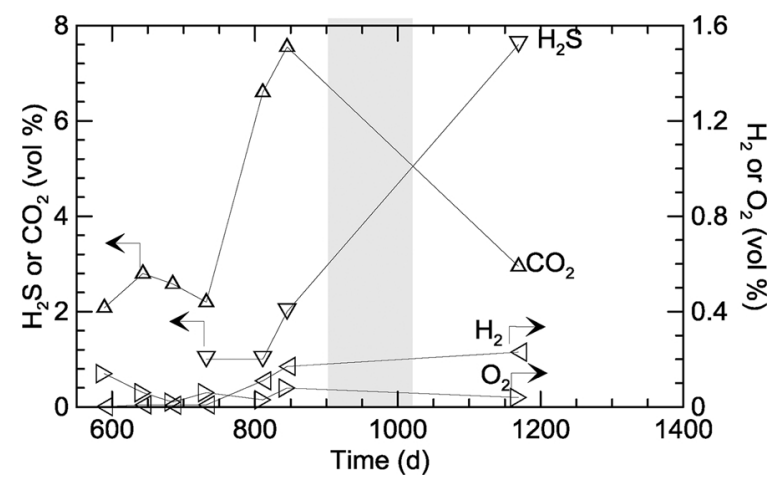

Fig. 3. Evolution of the gas phase composition in the test chamber.
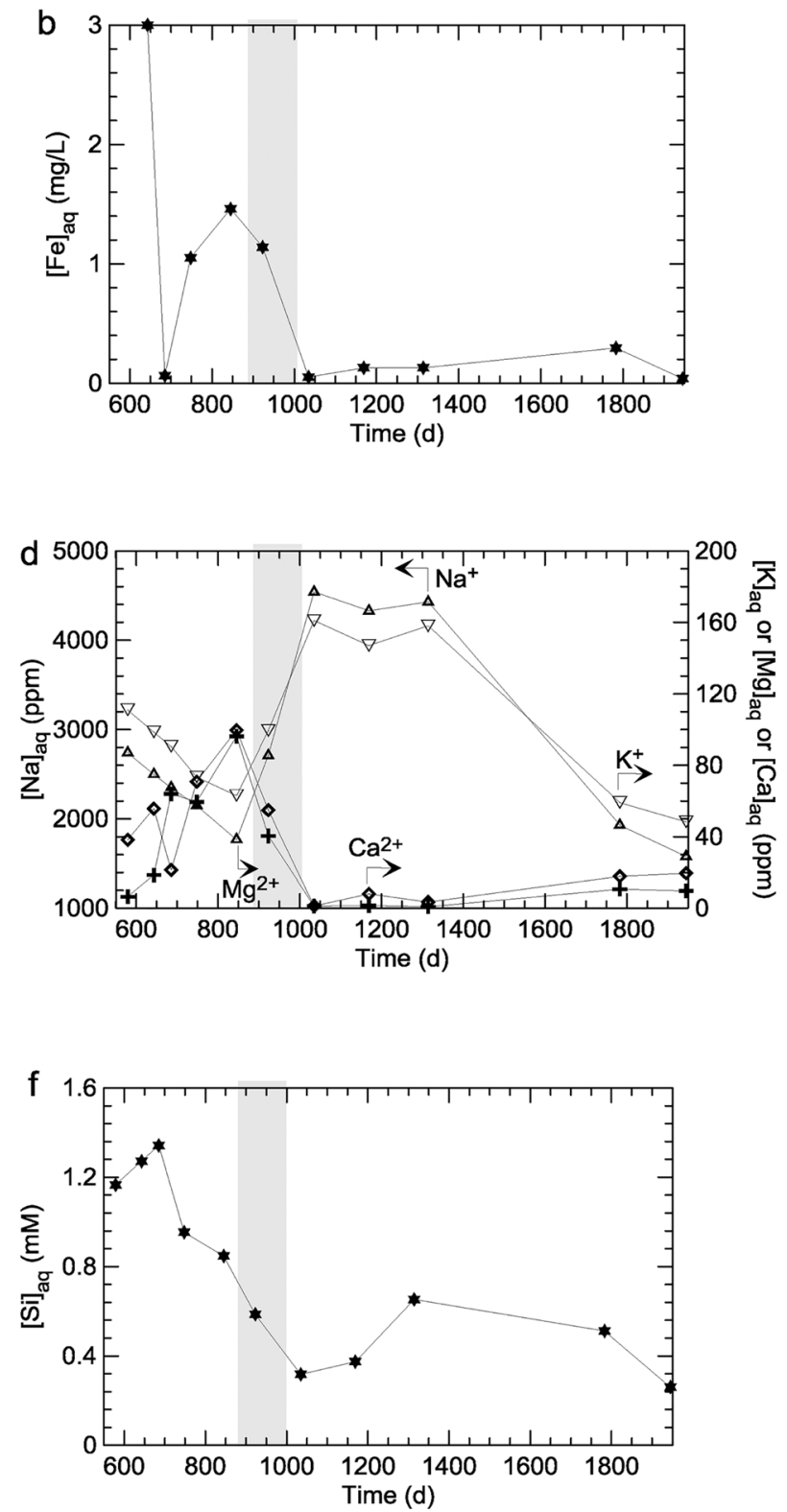

\subsection{Microbiological characterization}

\subsubsection{Microorganism enumeration}

The surfaces of Series 2 (reaction time of 104 days) and Series 3 (reaction times of 134-748 days) coupons showed relatively negligible prokaryote numbers (generally $<0.8$ units $/ \mathrm{cm}^{2}$; Table 3 ) compared to prokaryote concentrations measured in the porewater (Table 4). This suggests either that very few microorganisms are present in the CPs, or that these microorganisms cannot be cultivated in the standard conditions of MPN enumeration. In fact, it has been reported that microorganisms can strive on CPs or metal surfaces, but can have little affinity for suspension conditions [56]. Series 1-Rods 6-7 coupons, which were recovered after a reaction time of 870 days and between Series 2Rods 1-3 and Series 3-Rod 1, exhibited significantly higher surface density of microorganisms (from 3000 to 10000 cultivable units $/ \mathrm{cm}^{2}$ [51]. Higher densities of sulfurogen prokaryotes were also measured on the Series 3-Rods 3-4 coupons.

The sessile and planktonic population are dominated by thermophilic SRP and ThRP developing at $60{ }^{\circ} \mathrm{C}$ (Table 4), a temperature below 
Table 3

Results of microbiological analyses performed on samples reacted in the clay porewater.

\begin{tabular}{|c|c|c|c|c|c|c|c|}
\hline \multirow[b]{2}{*}{$\begin{array}{l}\text { Sample } \\
\text { Name }\end{array}$} & \multirow[b]{2}{*}{$\begin{array}{l}\text { Steel } \\
\text { grade }\end{array}$} & \multirow{2}{*}{$\begin{array}{l}\text { Removal time } \\
\text { (days) }\end{array}$} & \multirow[b]{2}{*}{$\begin{array}{l}\mathrm{T} \\
{ }^{\circ} \mathrm{C}\end{array}$} & \multicolumn{4}{|c|}{ microorganism population (units $/ \mathrm{cm}^{2}$ ) } \\
\hline & & & & SRP & ThRB & $\begin{array}{c}\text { Aerobic } \\
\text { prokaryotes }\end{array}$ & $\begin{array}{c}\text { Anaerobic } \\
\text { prokaryotes }\end{array}$ \\
\hline \multicolumn{2}{|c|}{ Series 2-Rod 1} & $\mathrm{t}_{0}+748$ & & & & & \\
\hline A282 & $\mathrm{P} 275$ & & 60 & 2 & 68 & 7 & 7 \\
\hline A242 & $\mathrm{P} 235$ & & 60 & 7 & 68 & 7 & 7 \\
\hline A262 & $\mathrm{P} 235 \mathrm{~s}$ & & 60 & 7 & 7 & 2 & 7 \\
\hline A284 & SA 516 & & 60 & $<2$ & 7 & $<2$ & 7 \\
\hline \multicolumn{2}{|c|}{ Series 2-Rod 2} & $\mathrm{t}_{0}+748$ & & & & & \\
\hline A285 & $\mathrm{P} 275$ & & 60 & 7 & 7 & $<2$ & 7 \\
\hline \multicolumn{8}{|c|}{ Series 2-Rod 3} \\
\hline A289 & P275 & & 60 & 7 & 7 & 7 & 7 \\
\hline Series 3-Rod 1 & SA 516 & $\mathrm{t}_{0}+1169$ & 60 & $<2$ & 6 & 6 & $<2$ \\
\hline \multicolumn{2}{|c|}{ Series 3-Rod-2 } & $\mathrm{t}_{0}+1314$ & & & & & \\
\hline \multirow[t]{2}{*}{ A296 } & P 275 & & 30 & $<0.8$ & $<0.8$ & $<0.8$ & $<0.8$ \\
\hline & & & 60 & $<0.8$ & $<0.8$ & $<0.8$ & $<0.8$ \\
\hline \multirow[t]{2}{*}{ A256 } & $\mathrm{P} 235$ & & 30 & $<0.8$ & $<0.8$ & $<0.8$ & $<0.8$ \\
\hline & & & 60 & 2.5 & $<0.8$ & $<0.8$ & $<0.8$ \\
\hline \multirow[t]{2}{*}{ A276 } & $\mathrm{P} 235 \mathrm{~s}$ & & 30 & $<0.8$ & $<0.8$ & $<0.8$ & $<0.8$ \\
\hline & & & 60 & $<0.8$ & $<0.8$ & $<0.8$ & $<0.8$ \\
\hline \multirow[t]{2}{*}{ A221 } & SA 516 & & 30 & $<0.8$ & $<0.8$ & $<0.8$ & $<0.8$ \\
\hline & & & 60 & $<0.8$ & $<0.8$ & $<0.8$ & $<0.8$ \\
\hline \multirow[t]{2}{*}{ A223 } & SA 516 & & 30 & $<0.8$ & $<0.8$ & $<0.8$ & $<0.8$ \\
\hline & & & 60 & $<0.8$ & $<0.8$ & $<0.8$ & $<0.8$ \\
\hline \multirow[t]{2}{*}{ A258 } & P235 & & 30 & $<0.8$ & $<0.8$ & $<0.8$ & $<0.8$ \\
\hline & & & 60 & $<0.8$ & $<0.8$ & $<0.8$ & $<0.8$ \\
\hline \multirow[t]{2}{*}{ A222 } & SA 516 & & 30 & $<0.8$ & $<0.8$ & $<0.8$ & $<0.8$ \\
\hline & & & 60 & $<0.8$ & $<0.8$ & $<0.8$ & $<0.8$ \\
\hline \multirow[t]{2}{*}{ A224 } & SA 516 & & 30 & $<0.8$ & $<0.8$ & $<0.8$ & $<0.8$ \\
\hline & & & 60 & $<0.8$ & $<0.8$ & $<0.8$ & $<0.8$ \\
\hline \multicolumn{2}{|c|}{ Series 3-Rod-3 } & $\mathrm{t}_{0}+1783$ & & & & & \\
\hline A298 & $\mathrm{P} 275$ & & 60 & $<1$ & 14 & $<1$ & $<1$ \\
\hline A259 & P235 & & 60 & $<1$ & 6 & $<1$ & $<1$ \\
\hline A278 & $\mathrm{P} 235 \mathrm{~s}$ & & 60 & $<1$ & 14 & $<1$ & $<1$ \\
\hline A226 & SA 516 & & 60 & 1.5 & 6 & $<1$ & $<1$ \\
\hline \multicolumn{2}{|c|}{ Series 3-Rod 4} & $\mathrm{t}_{0}+1783$ & & & & & \\
\hline A 300 & P275 & & 60 & $<1$ & 6 & $<1$ & $<1$ \\
\hline A211 & P235 & & 60 & $<1$ & 6 & $<1$ & $<1$ \\
\hline A280 & $\mathrm{P} 235 \mathrm{~s}$ & & 60 & 6 & 14 & $<1$ & $<1$ \\
\hline A212 & SA 516 & & 60 & 30 & 57 & $<1$ & $<1$ \\
\hline
\end{tabular}

"Only $80 \%$ of the sample surface was swabbed.

"Only $10 \%$ of the sample surface was swabbed.

nominal conditions of the test chamber $\left(85^{\circ} \mathrm{C}\right)$. After $\mathrm{t}_{0}+1035$ days, these populations gradually decrease. Interestingly, anaerobic (fermentary) prokaryotes were also detected during the heating breakdown, as well as aerobic/facultative anaerobic prokaryotes. This could result from the tightness loss of the test chamber, and from the DOC increase. Also, both aerobic microorganisms and SRP are detected in the porewater in contact with Series 3-Rod 2 samples, in contrast to the near-absence of comparable populations at the CPs surfaces. The most likely explanation is that CPs surfaces are occupied by consortia which are recalcitrant to cultivation.

Total microorganism enumeration by epifluorescence microscopy was performed only for the porewater sample collected at $\mathrm{t}_{0}+1314$ days. A value of $1.6 \times 10^{4}$ prokaryotes $/ \mathrm{mL}$ was obtained, not too far from the high number of aerobic prokaryotes detected by the MPN method. This value is also within a factor of three from the total density of planktonic prokaryotes measured by flux cytometry $\left(4.25 \times 10^{4}\right.$ prokaryotes $\left./ \mathrm{mL}\right)$. However, flux cytometry also revealed that only $0.7 \%$ of these were living cells. This low fraction suggests that microorganisms could have been harmed by changes in local conditions, such as change in $\mathrm{pH}$, or limited ingress of $\mathrm{O}_{2}$.

\subsubsection{Biomolecular analyses of planktonic microorganisms}

Molecular characterization of the porewater sample at $t_{0}+1314$ days has been performed to seek microbial strains not revivable in the MPN media. Enumeration using $\mathrm{qPCR}$ resulted in $1.5 \pm 0.3 \times 10^{4}$ Eubacteria $/ \mathrm{mL}$ and $5.8 \pm 0.2$ Archaea $/ \mathrm{mL}$. The amount of total prokaryotes compares well with the values obtained by flux cytometry and fluorescence counting.

The bands obtained after migration on DGGE gel and the peaks obtained by capillary electrophoresis-SSCP were reamplified by PCR with $16 \mathrm{~S}$ rDNA sequencing. Phylogenetic analysis identified the reamplicons as belonging to different prokaryote entities or operational taxonomic units (OTUs). The results of identification of the major and minor Eubacteria and Archaea obtained via PCR-DGGE cloning and PCR-SSCP cloning are reported in Table 5. Both DGGE and SSCP identified the three genera of Eubacteria as Pseudomonas (non-sporeforming facultative anaerobe), Desulfotomaculum (spore-forming strict anaerobe, sulfate-reducing), Pelotomaculum (non-spore-forming strict anaerobe), and four different genera of methanogenic (non-sporeforming strict anaerobes) Archaea, i.e. Methanolobus, Methanobrevibacter, Methanosphaera and Methanococcus. DGGE also identified one supplementary genus belonging to Eubacteria (Ferribacterium) and five genera belonging to Archaea that were missed by SSCP.

Note that the genus Desulfotomaculum corresponds to SRP with sporulation capabilities, hence able to withstand unfavorable conditions (such as in the MCO experiment) during a significant amount of time. The fact that methanogenic Archaea and spore-forming SRP were identified only by molecular biology, but not specifically enumerated 
Table 4

Results of microbiological analyses performed on the porewater for distinct reaction times. Aliquots cultured at $60{ }^{\circ} \mathrm{C}$.

\begin{tabular}{|c|c|c|c|c|c|c|}
\hline \multirow[t]{2}{*}{ Sample type } & \multirow[t]{2}{*}{ Reaction time (days) } & \multirow[t]{2}{*}{ Incubation $\mathrm{T}\left({ }^{\circ} \mathrm{C}\right)$} & \multicolumn{4}{|c|}{ Prokaryote population (units $/ \mathrm{cm}^{3}$ ) } \\
\hline & & & SRP & ThRP & Aerobic prokaryotes & Anaerobic prokaryotes \\
\hline Porewater & $\mathrm{t}_{0}+748^{\mathrm{a}}$ & 60 & 60 & 25 & 25 & $5 \times 10^{2}$ \\
\hline Series 2 water $^{\mathrm{b}}$ & & 60 & 25 & 2.5 & 2.5 & 2.5 \\
\hline Porewater & $\mathrm{t}_{0}+845^{\mathrm{c}}$ & 60 & 110 & 70 & 2.5 & $<0.5$ \\
\hline Porewater & $t_{0}+923^{d}$ & 60 & 250 & 2.5 & 2.5 & $<0.5$ \\
\hline \multirow[t]{2}{*}{ Porewater } & $t_{0}+1035^{e}$ & 30 & 25 & 200 & 50 & $<0.5$ \\
\hline & & 60 & 25 & 2.5 & 0.9 & $<0.5$ \\
\hline Porewater & $t_{0}+1169^{f}$ & 60 & 2.5 & 2.5 & $<0.5$ & $<0.5$ \\
\hline \multirow[t]{2}{*}{ Porewater } & $t_{0}+1314^{g}$ & 30 & $<0.5$ & $<0.5$ & 6 & $<0.5$ \\
\hline & & 60 & 25 & 25 & 25 & $<0.5$ \\
\hline \multirow[t]{2}{*}{ Series 3 -Rod 2 water ${ }^{b}$} & & 30 & 25 & $<0.5$ & 6000 & 250 \\
\hline & & 60 & 2.5 & $<0.5$ & 2500 & $<0.5$ \\
\hline \multirow[t]{2}{*}{ Porewater } & $t_{0}+1783^{h}$ & 30 & 2.5 & 25 & 2500 & 0.5 \\
\hline & & 60 & 2.5 & 250 & $<0.5$ & $<0.5$ \\
\hline \multirow[t]{2}{*}{ Series 3 -Rod 3 water $^{\mathrm{b}}$} & & 30 & $<0.5$ & $<0.5$ & $<0.5$ & $<0.5$ \\
\hline & & 60 & 2.5 & 200 & $<0.5$ & $<0.5$ \\
\hline
\end{tabular}

a sample collected with Series 2-Rods 1-3, during the first heating breakdown.

$\mathrm{b}$ water present in the steel cover during coupon recovery.

c collected with Series 1-Rod 5 (see [51]).

d collected with Series 1-Rod 6-7 (see [51]).

e collected at the introduction of Series 3-Rods 1-4.

${ }^{\mathrm{f}}$ collected with Series 3-Rod 1.

${ }^{\mathrm{g}}$ collected with Series 3-Rod 2.

${ }^{\mathrm{h}}$ collected with Series 3-Rod 3.

by MPN demonstrates the complementarity of cultural and molecular approaches to be closer to the full assessment of the microorganism content in porewater. Also, molecular-based methodologies give access to names of genera or species of microorganisms, but only with qualitative and semi-quantitative information, because of several biases (during DNA extraction, amplification, choice of primers, and colocation of sequences, to name a few).

\subsection{Corrosion processes}

Two distinct corrosion behaviours were observed for the samples corroded in the liquid phase (Fig. 4). For Series 3-Rods 1-2, $\mathrm{e}_{\text {cor }}$ was limited to less than $1 \mu \mathrm{m}$, except for one P235 sample $(6.8 \mu \mathrm{m}$ at $\mathrm{t}_{3}+279$ days). In contrast, $\mathrm{e}_{\text {cor }}$ for the Series 2-Rods 1-3 and Series 3Rods 3-4 coupons span the $[4.7,5.5]$ and $[14.5,38.3] \mu \mathrm{m}$ ranges, respectively. All the average rates of corrosion are lower than $19 \mu \mathrm{m} / \mathrm{a}$, but the discrepancy clearly suggests that changes in temperature affect the corrosion rate. The microscopic origins for these discrepancies will be examined now.

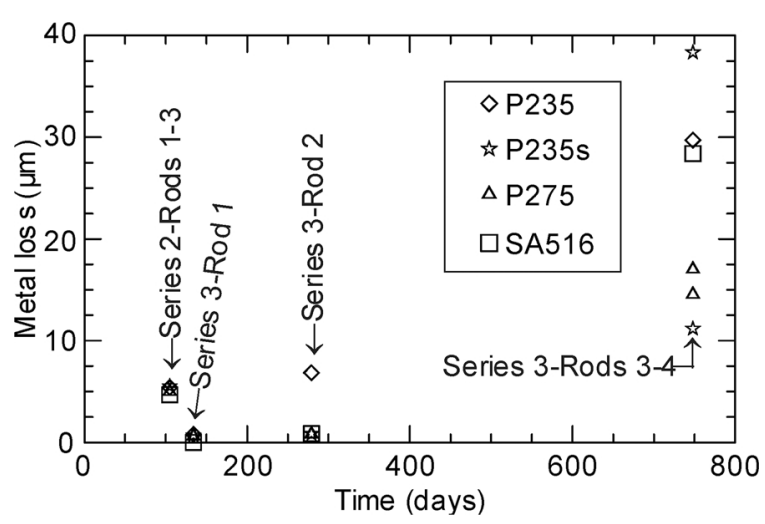

Fig. 4. Evolution of metal loss in the borehole water of the test chamber.

\subsubsection{Macroscopic characterizations}

Macroscopic views show that the surface of samples from Series 3Rods $1-2$ is smooth and essentially covered with either light or dark

Table 5

List of genera and species identified by PCR-DGGE and PCR-SCCP in the porewater collected at $t_{0}+1314$ days. The numbers in brackets indicate the homology percent and the number of clones.

\begin{tabular}{|c|c|c|}
\hline $\begin{array}{l}\text { Prokaryote } \\
\text { type }\end{array}$ & PCR-DGGE/cloning & PCR-SSCP/cloning \\
\hline Major & Pseudomonas nitratoreducens ${ }^{a}$ & Pseudomonas stutzeri ${ }^{a}$ \\
\hline Eubacteria & Pseudomonas sp. or Ps. pseudoalcaligenes ${ }^{a}$ & \\
\hline & 1 unidentified major OTU ${ }^{\mathrm{c}}$ & Pelotomaculum sp. or $\boldsymbol{P}$. isophtalicicum ${ }^{b}$ \\
\hline Minor & Ferribacterium limneticum ${ }^{a}$ & Pelotomaculum schinckii ${ }^{a}$ \\
\hline Eubacteria & $\begin{array}{l}\text { Desulfotomaculum auripigmentum }{ }^{a} \\
\text { Pelotomaculum thermopropionicum }^{b}\end{array}$ & $\begin{array}{l}\text { Desulfotomaculum sp. or } \boldsymbol{D} \text {. } \text { arcticum }^{b} \\
11 \text { unidentified minor OTU }\end{array}$ \\
\hline $\begin{array}{l}\text { Major } \\
\text { Archaea }\end{array}$ & Uncultured thermophilic euryarchaeon & Absence of peak after PCR \\
\hline $\begin{array}{l}\text { Minor } \\
\text { Archaea }\end{array}$ & $\begin{array}{l}\text { - Methanococcus aeolicus }{ }^{b} \\
\text { - Methanosphaera cuniculi }{ }^{b} \\
\text { - Methanobrevibacter smithii or M. } \text { oralis }^{b} \\
\text { - Methanolobus profundi } \\
\quad \text { or M. bombayensis }{ }^{b}\end{array}$ & Absence of peak after PCR \\
\hline
\end{tabular}

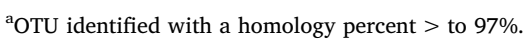

bI OTU identified with a homology percent $<$ to $97 \%$.

cOTU not amplified.

In bold: OTU identified as the same genera both with the two techniques (DGGE \& SSCP). 


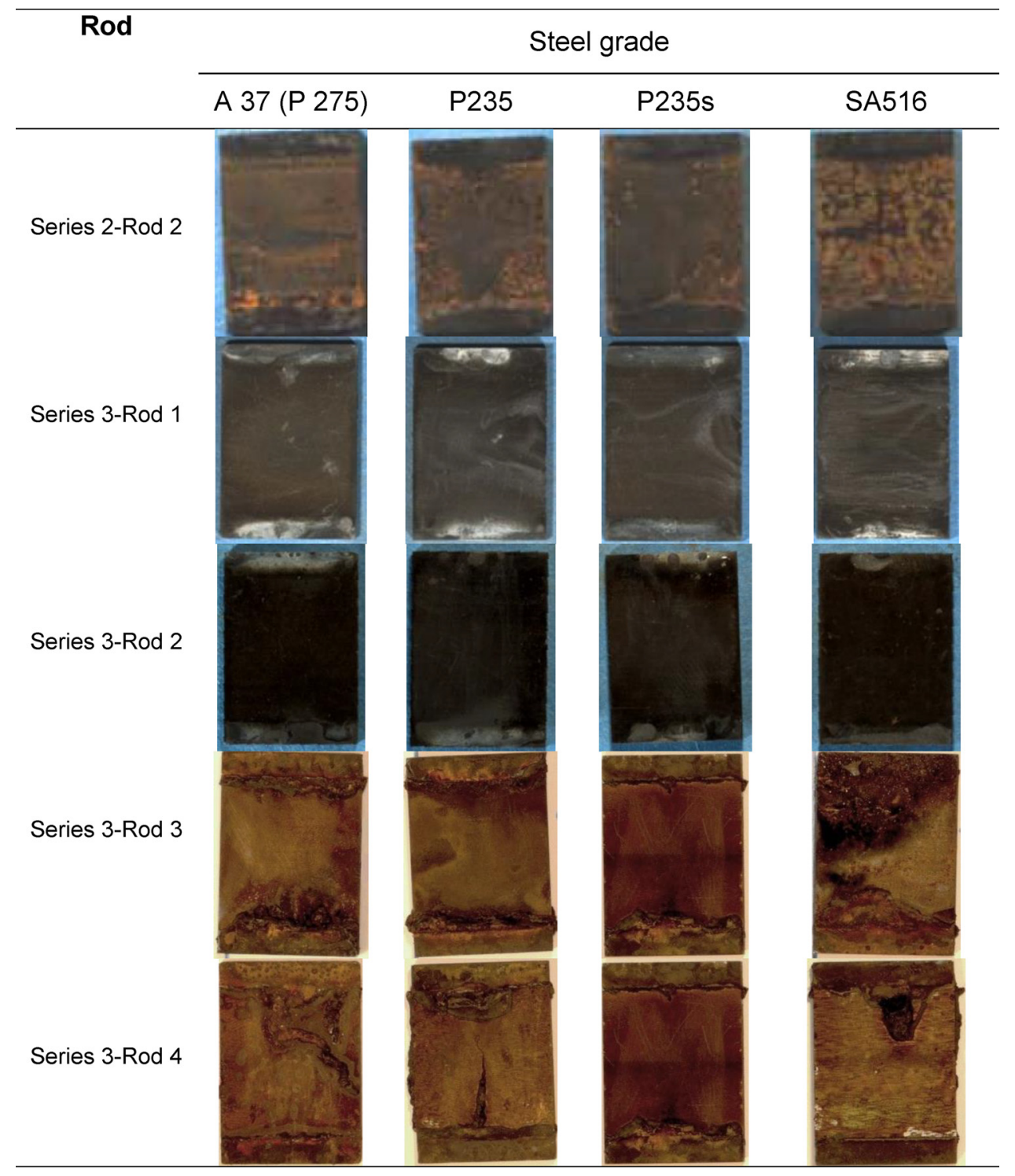

Fig. 5. Macrograph of coupons reacted in the borehole water showing the apparent evolution of the corrosion facies.

greyish material (Fig. 5). Light-grey deposits are observed on the coupon short ends, which are usually inserted in the sample holder. The coupons from Series 2-Rods 1-3 also seem to be covered with a browngrey layer, except near the coupon short ends which are distinctively black. In contrast, coupons from Series 3-Rods 3-4 are covered by redbrown deposits, forming thin linear bulges at about $2-3 \mathrm{~mm}$ from the coupon short end (Fig. 5). The surface itself can also be covered by redbrown bulges and tubercles. Thus $\mathrm{e}_{\text {cor }}$ correlates with the amount of surface deposits, which likely correspond to CPs.

Cross sections (Fig. 6) show that there is no corrosion indent, and corrosion layers are not visible for shorter reaction times (A241 and A261 coupons). In contrast, A213 (Series 3-Rod 3) and A260 (Series 3Rod 4) coupons display visible depressions, usually close to the extremities, suggesting heterogeneous corrosion. These corroded areas coincide with the bulges and massive deposits. Away from these tubercles, the C-steel surfaces seem smooth and free of thick CPs layers. Microscopic analysis showed that these heterogeneities in local damage are mirrored by distinct compositions of CPs.

\subsubsection{Corrosion of samples series 3-rods $1-2$ (reacted at $85^{\circ} \mathrm{C}$ only)}

The BSE images of cross-sections from Series 3-Rods 1-2 coupons show that the metal surface is generally flat and covered by a very thin
CPs layer (Fig. 7). The absence of significant roughening of the metalCPs interface confirms that corrosion is quite limited, in agreement with gravimetric results. The CPs layer is surprisingly thin ( $\leq 5 \mu \mathrm{m}$ over most of the interface). Chemical maps and EDX quantification (Table 6) indicate that this layer is enriched in $\mathrm{Mg}, \mathrm{Si}$, and, to a lesser extent, $\mathrm{Na}$. For the A274 interface, local $\mathrm{Na}, \mathrm{Mg}, \mathrm{Si}$ and Fe contents amounted to $6.3-8.8,2.8-4.7,11.8-15$, and $11-12$ at.\%, respectively, whereas the $\mathrm{Al}$ content ( $\leq 0.7$ at.\%) was close to detection limit. The O content was about 60 at.\% for all PI, a value not far from that expected if all cations were present as oxides, suggesting that the amount of hydroxide or carbonate is limited. The $(\mathrm{Mg}+\mathrm{Fe}) / \mathrm{Si}$ ratio is quite stable near 1.09-1.14, a value intermediate between TO dioctahedral and trioctahedral phyllosilicate (1.0 and 1.5, respectively). However, the layer also contains a significant amount of $\mathrm{Na}(6.4-8.8$ at.\%). Sodium is known to balance the permanent layer charge of TOT phyllosilicate [57], but TO phyllosilicate do not have significant layer charge [58], Also, amounts of detected $\mathrm{O}$ are significantly smaller than expected for TO phyllosilicate, for which four out of nine $\mathrm{O}$ atoms per unit cell correspond to hydroxyl groups. This suggests the prevalence of TOT phyllosilicate, with, perhaps, a small amount of TO polytypes.

The local composition of PI for sample A257 compares with A274 (Table 6). Again, Fe, $\mathrm{Mg}$ and $\mathrm{Si}$ contents result in $(\mathrm{Fe}+\mathrm{Mg}) / \mathrm{Si}$ ratios 

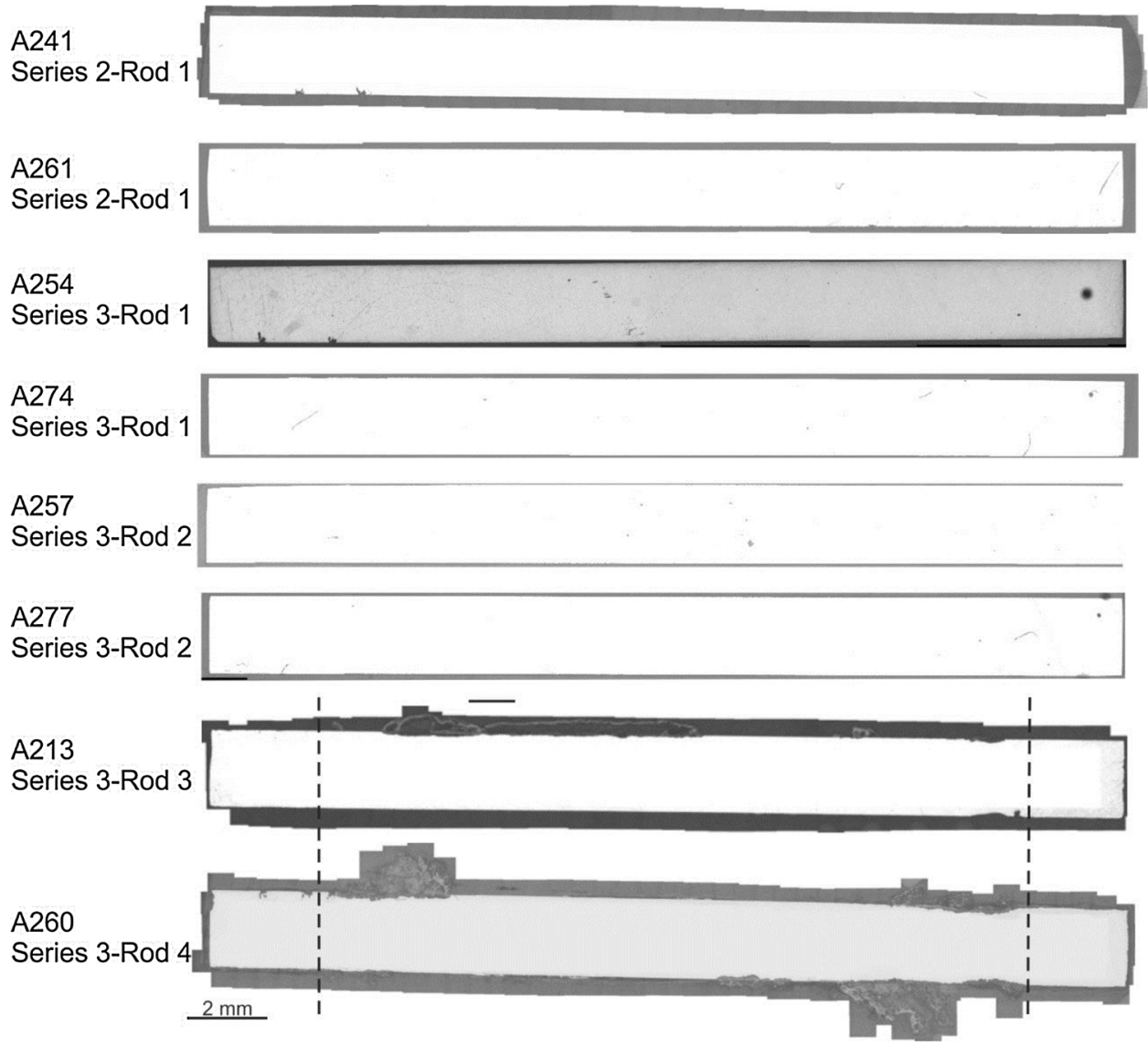

Fig. 6. Comparison of the cross-sections of P235 and P235 s coupons recovered from the successive rods. The indents on sample A254 correspond to coupon engraving.

between 1.11 and 1.16, except for PI 2, a protruding grain, for which this ratio equals 1.6 (possibly due to the presence of small amounts of oxide). A fair amount of Na was also present, probably as a chargecompensating cation in TOT phyllosilicate.

In conclusion, the free surface of samples reacted at $85^{\circ} \mathrm{C}$ only is flat and essentially covered by a thin layer of Fe silicate. No extended corrosion occurred, consistent with the presence of a solid-state protective barrier.

\subsubsection{Corrosion of series 2-rods 1-2 and series 3-rods 3-4}

Cross-section from Series 2-Rods 1-3 and Series 3-Rods 3-4 coupons reveal that the metal-CPs interfaces are significantly roughened (Fig. 8). For slightly damaged areas, depressions of a few $\mu \mathrm{m}$ are observed, often covered by CPs layers with thicknesses between 5 and $20 \mu \mathrm{m}$ (Fig. 8a-d). These layers have a loose structure, with vacancies and fractures parallel and perpendicular to the corrosion interface, sometimes resulting in CPs flaking. Coupons from Series 3-Rods 3-4 also show depressions as deep as $200 \mu \mathrm{m}$, filled with CPs, and covered with outer deposits locally as thick as about $1000 \mu \mathrm{m}$ (Fig. 8e,f). These significantly corroded areas correspond to the bulges and tubercles observed on about $10 \%$ of the surface for samples A213 and A260. The transitions between depressions and slightly damaged areas is sharp, sometimes over distances shorter than a few $\mu \mathrm{m}$ (Fig. 8g,h).

Typical EDX chemical maps for Series 2-Rods 1-3 samples (reaction time of 105 days) reveal some lateral variability in CPs chemical composition (Fig. 9). In some areas, the CPs layers are essentially made of $\mathrm{O}$ and $\mathrm{Fe}$ (Fig. 9a), possibly with $\mathrm{H}$ and $\mathrm{C}$ which cannot be quantified by EDX. Quantitative analysis yielded $\mathrm{O}$ and Fe contents of 55 and 33-34 at.\%, respectively, for the innermost layer, and 51 and 38-39 at.\% for the outermost layer (Table 7, sample A261). This resulted in $\mathrm{O} / \mathrm{Fe}$ ratio between 1.29 (outer $\mathrm{CPs}$ ) and 1.65 (inner $\mathrm{CPs}$ ), suggesting the formation of $\mathrm{Fe}$ oxide such as magnetite $(\mathrm{O} / \mathrm{Fe}=4 / 3)$ or hematite $(\mathrm{O} /$
$\mathrm{Fe}=3.2$ ). Magnetite was identified by $\mu$ XRD (Fig. 10). The layer also contained significant amounts of S (1.1-1.4 at.\%), and, surprisingly, Na (6.4-7.2 at.\%). The high Na content could result from drying of residual porewater, but this hypothesis is invalidated by the low $\mathrm{Cl}$ content ( $<0.4$ at.\%). Also, Na retention by TOT phyllosilicates can be ruled out because of the low silicate content. The only other explanations are either $\mathrm{Na}$ incorporation in a $\mathrm{Fe}$ solid phase, or precipitation as $\mathrm{Na}$ (hydrogeno)carbonate.

In other areas, both the inner and other CPs are significantly more enriched in O (62-65 at.\%) and depleted in Fe (27-31 at.\%), leading to $\mathrm{O} / \mathrm{Fe}$ ratios of $2 / 1$ which are rather consistent with oxide/hydroxide phases (Table 7, sample A241, PI 1-2 and 5-6). It can be noted that Si content is also significant in the median and outer parts of the CPs layer (Table 7, sample A241, PI 3-4), and S fairly abundant (from 1.8 to 3.7 at.\%). The $\mathrm{Fe} / \mathrm{Si}$ ratio in the median layer equals $\sim 1.5-1.7$, a value expected for Fe(II)-containing TO phyllosilicate. Note however that $\mathrm{S}$ could be present in the layer as Fe sulfide, which would lower the amount of $\mathrm{Fe}$ incorporated in other phases. Assuming the effective presence of FeS, then the ratio of residual $\mathrm{Fe}$ over Si decreases to 1.2-1.5, intermediate between the values of TO trioctahedral and dioctahedral phyllosilicate. Interestingly, the Na content in the CPs of this area is lower than 1.1 at.\%, a sixfold decrease compared to Si-poor areas, confirming that $\mathrm{Na}$ in these layers is unrelated to the formation of phyllosilicate. Overall, these results indicate that CPs are essentially made of Fe (hydr)oxide, and, locally, Fe silicate and S-containing solids.

For Series 3- Rods 1-2 coupons, at least two distinct types of interfacial domains can be identified. In some areas, corrosion layers are quite thin (Fig. 8c,d), and the sample surface is smooth (Fig. 11a-c), and partially covered by euhedral particles (Fig. 11d-e). In some flaked areas (Fig. 11b), at least three successive layers with distinct compositions can be identified (Fig. 11c). The innermost layer is enriched in $\mathrm{O}, \mathrm{Si}$, and Fe (Fig. 11c), suggesting the formation of Fe silicate. This 
a
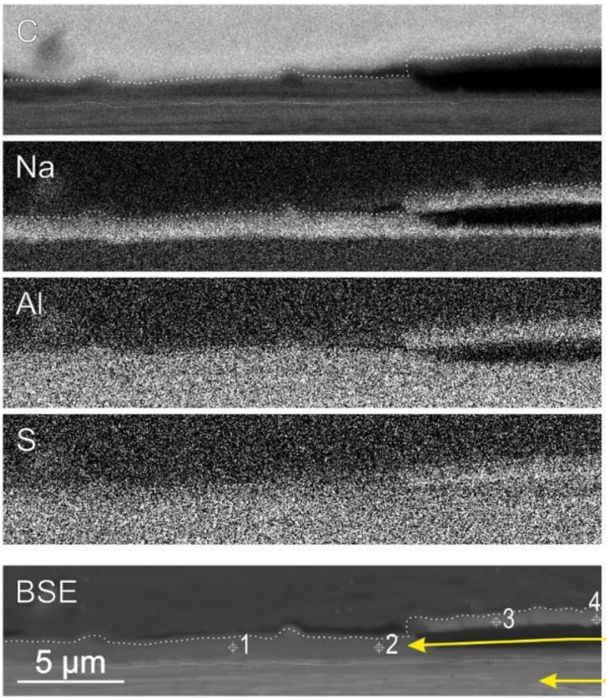

b
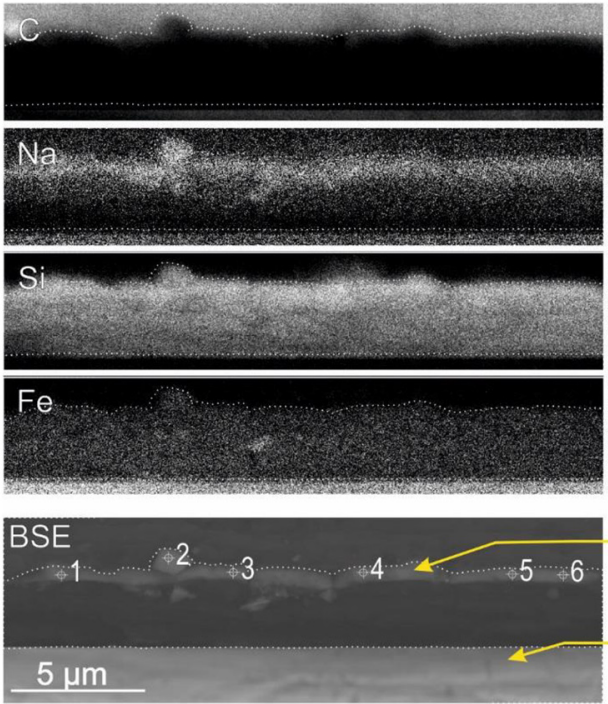
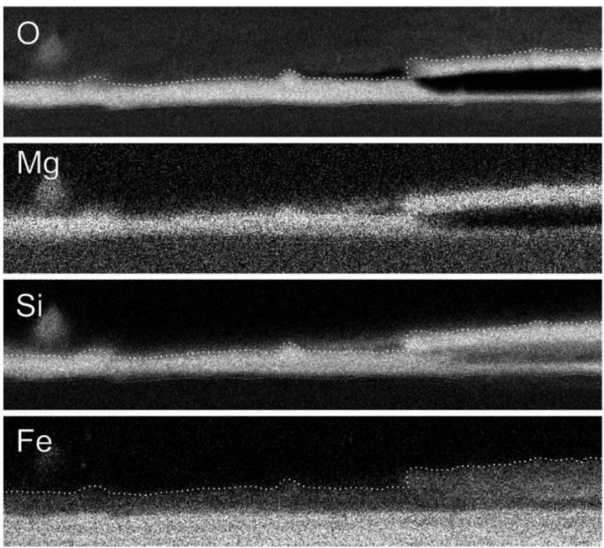

layer of corrosion products metal
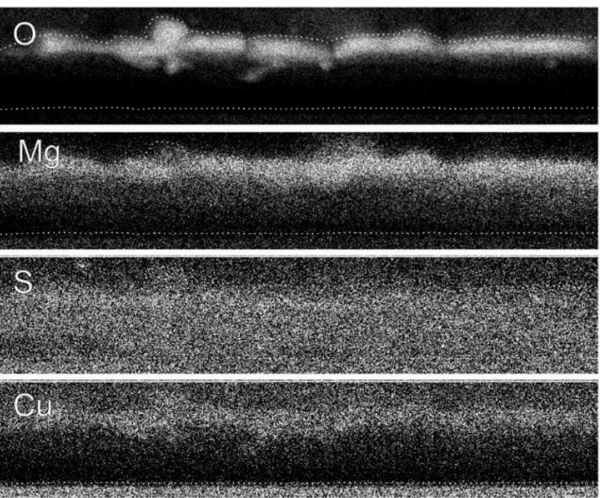

layer of corrosion products

metal

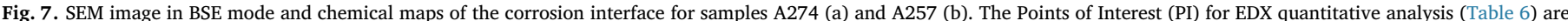
indicated on the BSE images.

Table 6

Quantification of SEM-EDX analyses for the coupons reacted for 134 days (A274) and 279 days (A257) at $85^{\circ} \mathrm{C}$ only. Points of Interest (PI) are indicated on Fig. 7.

\begin{tabular}{|c|c|c|c|c|c|c|c|c|c|c|c|c|c|}
\hline \multirow[t]{2}{*}{ Sample } & \multirow[t]{2}{*}{ PI } & \multirow[b]{2}{*}{$\mathrm{O}$} & \multicolumn{11}{|c|}{ Composition (at.\%) } \\
\hline & & & $\mathrm{Na}$ & $\mathrm{Mg}$ & $\mathrm{Al}$ & $\mathrm{Si}$ & $\mathrm{S}$ & $\mathrm{Cl}$ & $\mathrm{K}$ & $\mathrm{Ca}$ & $\mathrm{Fe}$ & $\mathrm{Cu}$ & $\mathrm{Zn}$ \\
\hline \multirow[t]{4}{*}{ A274 } & 1 & 59.8 & 6.3 & 4.7 & 0.7 & 15.0 & 0.2 & 0.5 & 0.1 & 0.0 & 11.9 & 0.6 & 0.2 \\
\hline & 2 & 63.9 & 8.8 & 2.8 & 0.5 & 11.8 & 0.3 & 0.4 & 0.1 & 0.0 & 10.7 & 0.5 & 0.2 \\
\hline & 3 & 60.4 & 7.0 & 4.0 & 0.6 & 14.4 & 0.3 & 0.4 & 0.1 & 0.0 & 11.9 & 0.5 & 0.2 \\
\hline & 4 & 59.6 & 6.4 & 4.6 & 0.5 & 15.4 & 0.2 & 0.4 & 0.1 & 0.0 & 12.2 & 0.5 & 0.1 \\
\hline \multirow[t]{6}{*}{ A257 } & 1 & 56.9 & 5.5 & 4.0 & 0.7 & 16.2 & 0.9 & 0.1 & 0.2 & 0.0 & 14.5 & 0.7 & 0.3 \\
\hline & 2 & 59.4 & 5.6 & 2.4 & 0.5 & 12.6 & 0.4 & 0.2 & 0.2 & 0.0 & 17.6 & 0.6 & 0.3 \\
\hline & 3 & 61.8 & 3.6 & 4.3 & 0.6 & 15.4 & 0.3 & 0.1 & 0.1 & 0.0 & 13.1 & 0.5 & 0.2 \\
\hline & 4 & 61.2 & 4.0 & 4.4 & 0.8 & 15.3 & 0.4 & 0.1 & 0.1 & 0.0 & 12.6 & 0.6 & 0.2 \\
\hline & 5 & 61.1 & 3.7 & 4.6 & 0.6 & 15.5 & 0.2 & 0.1 & 0.1 & 0.0 & 13.4 & 0.5 & 0.2 \\
\hline & 6 & 61.5 & 3.5 & 4.6 & 0.7 & 15.6 & 0.2 & 0.1 & 0.1 & 0.0 & 13.1 & 0.5 & 0.2 \\
\hline
\end{tabular}

innermost layer is also visible on cross-sections of these areas (Fig. 12). Quantitative analysis (Table 8, PI 1) yields Fe, Mg and Si amounts of 19, 3.8 and 13.7 at.\%, hence a $(\mathrm{Fe}+\mathrm{Mg}) / \mathrm{Si}$ ratio of 1.7. Over this innermost unit, an homogeneous and discontinuous layer enriched in $\mathrm{Fe}, \mathrm{Cu}$ and $\mathrm{S}$ can be observed (Fig. 12). Chemical analysis showed that this layer is significantly depleted in $\mathrm{O}(\leq 15$ at.\%), and contains similar amounts of $\mathrm{Fe}$ and $\mathrm{Cu}$ (Table 8, PI 2-3). This suggests either the formation of a mixed $(\mathrm{Fe}, \mathrm{Cu})$ sulfide or the coexistence of $\mathrm{Fe}$ and $\mathrm{S}$ sulfide. This sulfide layer is covered by a compact external layer forming most of the exposed surface, with a composition more enriched in $\mathrm{Mg}$ and depleted in Fe than the silicate innermost layer (Table 8, PI 4). The $(\mathrm{Fe}+\mathrm{Mg}) / \mathrm{Si}$ chemical ratio $(1.6 \pm 0.1)$ is in reasonable agreement with the composition of TO phyllosilicate (greenalite). Finally, the presence of outer euhedral particles is consistent with growth in free solution (Fig. 11d,e). Some of these solid have a squat rhomboedreal shape and a chemical composition corresponding to Ca-rich Fe carbonate, i.e. ankerite (Fig. 11d). Other solid phases seem to be made of small thin foils, sometimes stacked together to form particles with triangular prism shape (Fig. 11e,f). The Fe and Si content of these particles are about 20.6 and 6.1 at.\%, respectively, with leads to a $\mathrm{Fe} / \mathrm{Si}$ ratio of 3.5. Both the triangular prismatic shape and the high $\mathrm{Fe} / \mathrm{Si}$ ratio allow to identify these crystals as cronstedtite ([Fe(II) $\left.)_{3-\mathrm{x}} \mathrm{Fe}(\mathrm{III})_{\mathrm{x}}\right]\left[\mathrm{Fe}(\mathrm{III})_{\mathrm{X}} \mathrm{Si}_{2-\mathrm{x}}\right]$ $\left.\mathrm{O}_{5}(\mathrm{OH})_{4}\right)$ [59]. From the $\mathrm{Fe} / \mathrm{Si}$ ratio, $\mathrm{x}$ can be calculated, and equals 0.89 , a value slightly small than for nominal cronstedtite $(x=1)$, but larger than for most natural polytypes [60]. Interestingly, the imaged surface did not charge under the electron beam, even though no electrically conducing coating was deposited. This indicates that these layers were fairly correct electron conducers. 


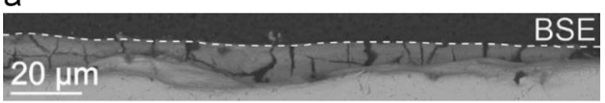

C
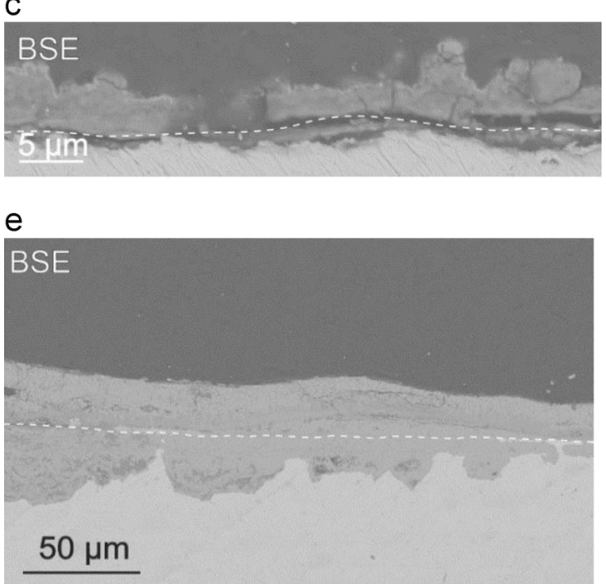

g

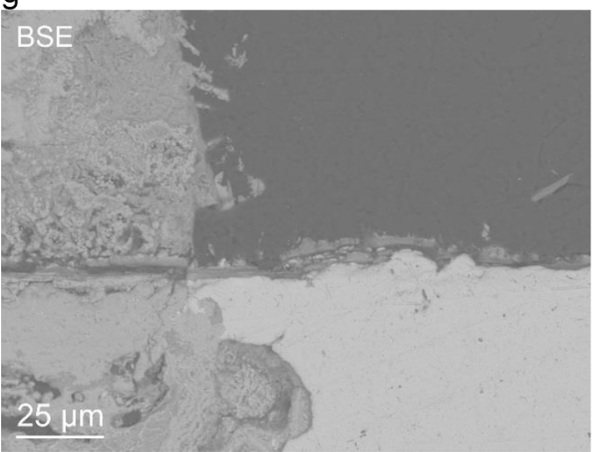

b

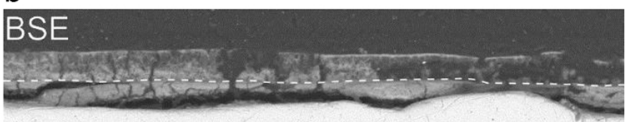

$\underline{20 \mu \mathrm{m}}$

d

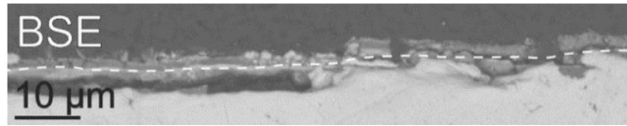

f

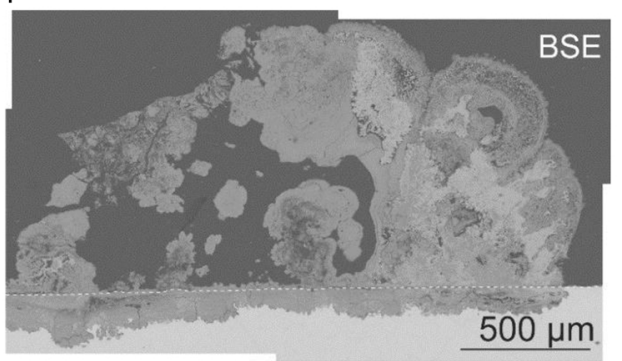

$\mathrm{h}$

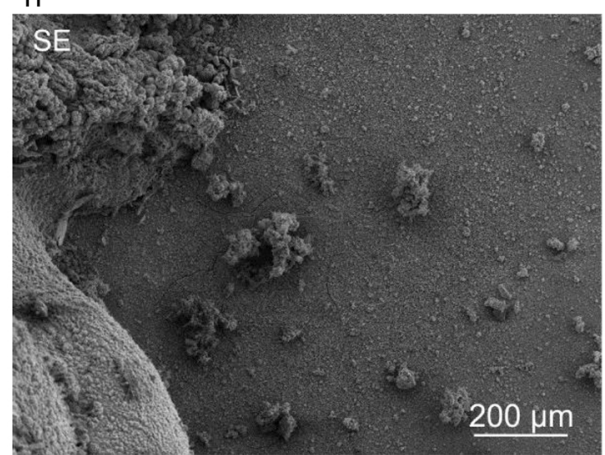

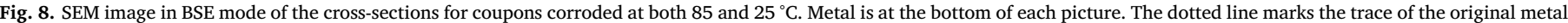

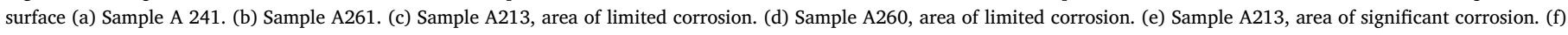
Sample A260, area of significant corrosion. (g,h) Images in BSE and Secondary Electron (SE) modes of the transition between areas of limited and extended corrosion.

In contrast to this relatively simple structural organization, areas of extensive corrosion are quite heterogeneous. First, essentially $\mathrm{O}$ and $\mathrm{Fe}$ are detected in the inner CPs, with contents of 59-71 and 25-39 at.\%, respectively, suggesting coexistence of several distinct phases (Table 9 , PI 1-5). Local $\mu$ Raman analyses (Figs. 13 and 14a,b) and $\mu$ XRD (Fig. 14g, patterns B060-B090) confirmed the prevalence of magnetite and chukanovite. Also, the S content close to the steel-CPs interface can be locally quite significant (up to 1.6 at.\%; Table 9, PI 4-5), as is the case of $\mathrm{Cl}$ (up to 2.6 at.\%; Table 9, PI 3). In some areas, the Cl-rich CPs actually individualize as an interfacial layer of a Cl-rich solid (Fig. 15a), identified by $\mu$ XRD (Fig. 15b, patterns A050-A090) and $\mu$ RS (Fig. 15c) as $\beta-\mathrm{Fe}_{2}(\mathrm{OH})_{3} \mathrm{Cl}$.

Closer to the trace of the original surface, $\mathrm{O}$ and Fe contents of $\sim 75$ and $\sim 24$ at.\% suggest the occurrence of siderite (Table 9, PI 6-7). This occurrence was confirmed by $\mu \mathrm{XRD}$ (Fig. 14g, pattern B150). The trace of the original surface is clearly visible as a discontinuous fringe enriched in $\mathrm{Si}, \mathrm{Mg}, \mathrm{S}$ and $\mathrm{Cu}$ (Fig. 13). This trace is actually made of two joint sublayers of Fe-rich silicate sandwiched between two discontinuous layers of magnetite (Fig. 15). This interfacial fringe is in lateral continuity with CPs units present in areas with limited corrosion. Here however, these fringes are embedded in $\mathrm{CP}$, meaning that extensive corrosion occurred after the formation of the initial corrosion interface.

Finally, the outer CPs are heterogeneous in composition (Fig. 13). In some areas, Fe and O only are detected (e.g. Table 9, PI 8-9 and 11-12). $\mu$ Raman analysis (Fig. 14c-d) and $\mu$ XRD (Fig. 14e) indicate association of siderite and magnetite. In other areas, $\mathrm{Mg}$ and $\mathrm{Si}$ values up to 1.3 and
10 at.\% are measured (e.g. Table 9, PI 13-15), consistent with the precipitation of $(\mathrm{Fe}, \mathrm{Mg})$ silicate.

\subsubsection{Nature of corrosion products on coupons extremities}

Coupon extremities, corresponding to areas inserted in PEEK sample holders, share some similarities in terms of nature and composition of $\mathrm{CPs}$. The corrosion interfaces are made of a thin $(<10 \mu \mathrm{m})$ layer of $\mathrm{Fe}$ silicate close to steel, and an outer layer (Fig. 16a,b) shown by $\mu$ XRD and $\mu \mathrm{RS}$ to be made of rhombohedral carbonate. For shorter reaction times (e.g. sample A241, 104 days of reaction) this carbonate layer can be fragmentary (Fig. 17, sample A241), and is made of (Ca,Mg)-containing ankerite (Table 10, A241 sample, PI 4-7). For longer reaction times, the particles have a typical desert rose-like morphology (Fig. 16a), and they coalesced to form a crackled compact layer (Fig. 16b). The ankerite is restricted to the vicinity of the steel surface for the longer reaction times (Table 10, A260 sample, PI 5-7), and outer Fe carbonate to almost pure siderite (Table 10, A260 sample, PI 8). This gradual from ankerite to siderite is in line with the depletion of the seeping water in $\mathrm{Ca}$ and $\mathrm{Mg}$.

\section{Discussion}

\subsection{Physico-chemical evolution of the seeping porewater}

Series 2 and Series 3 rods were introduced in the reaction chamber when slightly basic conditions were restored after an acidic transient. Basic $\mathrm{pH}$ values were considered representative of the long-term 
a
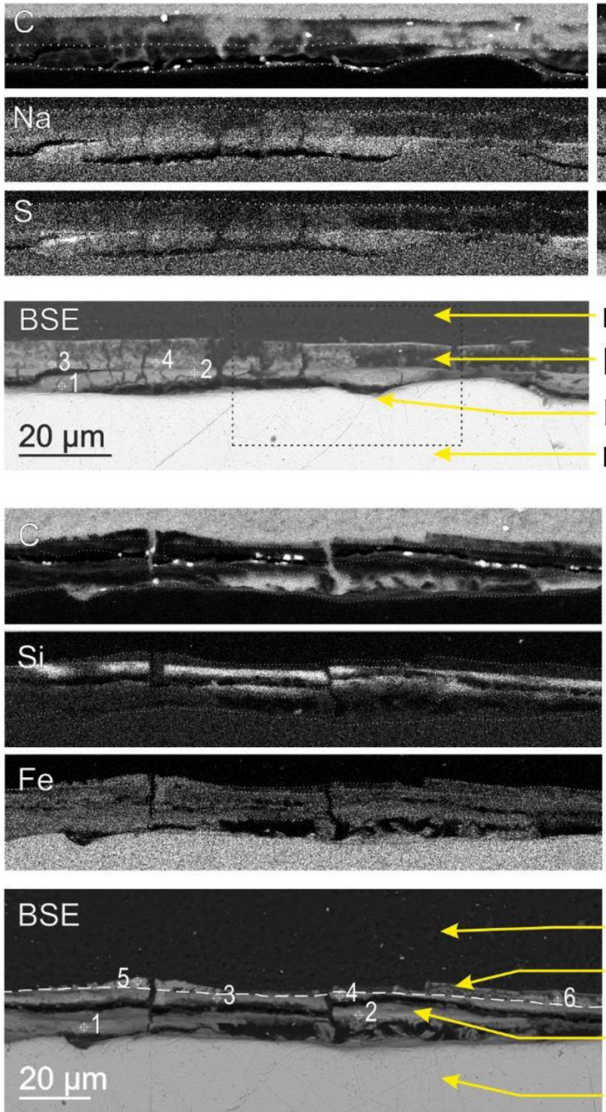
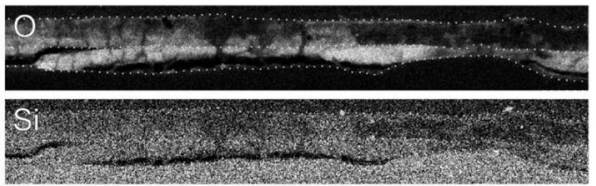

$\mathrm{Fe}$
Fig. 9. SEM image in BSE mode and chemical maps of the cross sections for samples A241 and A261. The dashed line locates the trace of the original surface. The Points of Interest (PI) for EDX quantitative analysis given in Table 7 are indicated on the BSE image. ECP: external corrosion products; ICP: Internal corrosion products. (a) Example of Si-rich $\mathrm{CP}$ units (A261 sample). (b) Example of Si-poor CP units (A241 sample).

\section{resin \\ ECP layer}

ICP layer metal

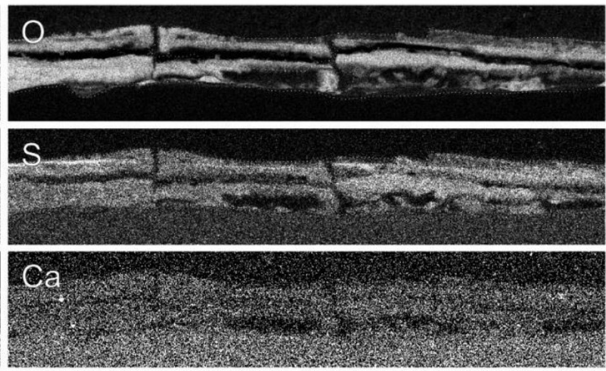

resin

ECP layer

ICP layers

metal

Table 7

Quantification of SEM-EDX analyses for coupons A241 and A261 (both reacted at $85{ }^{\circ} \mathrm{C}$ and $25{ }^{\circ} \mathrm{C}$ for 105 days). Points of Interest (PI) are indicated on Fig. 9.

\begin{tabular}{|c|c|c|c|c|c|c|c|c|c|c|c|c|c|}
\hline \multirow[t]{2}{*}{ Sample } & \multirow[t]{2}{*}{ PI } & \multirow[b]{2}{*}{$\mathrm{O}$} & \multicolumn{11}{|c|}{ Composition (at.\%) } \\
\hline & & & $\mathrm{Na}$ & $\mathrm{Mg}$ & $\mathrm{Al}$ & $\mathrm{Si}$ & $\mathrm{S}$ & $\mathrm{Cl}$ & $\mathrm{K}$ & $\mathrm{Ca}$ & $\mathrm{Fe}$ & $\mathrm{Cu}$ & $\mathrm{Zn}$ \\
\hline \multirow[t]{4}{*}{ A261 } & 1 & 55.4 & 6.2 & 0.6 & 0.3 & 0.5 & 1.3 & 0.1 & 0.1 & 0.2 & 34.3 & 0.8 & 0.2 \\
\hline & 2 & 54.8 & 7.2 & 0.8 & 0.4 & 0.5 & 1.4 & 0.2 & 0.1 & 0.2 & 33.2 & 0.9 & 0.3 \\
\hline & 3 & 50.7 & 6.5 & 0.5 & 0.2 & 0.5 & 1.4 & 0.4 & 0.1 & 0.2 & 38.4 & 0.8 & 0.2 \\
\hline & 4 & 50.7 & 6.4 & 0.6 & 0.3 & 0.4 & 1.1 & 0.3 & 0.1 & 0.2 & 39.2 & 0.6 & 0.1 \\
\hline \multirow[t]{6}{*}{ A241 } & 1 & 65.2 & 0.7 & 0.3 & 0.2 & 0.4 & 1.8 & 0.1 & 0.1 & 0.1 & 30.4 & 0.5 & 0.2 \\
\hline & 2 & 62.3 & 1.1 & 0.4 & 0.2 & 2.0 & 3.3 & 0.1 & 0.0 & 0.2 & 29.7 & 0.6 & 0.1 \\
\hline & 3 & 53.0 & 1.0 & 0.8 & 0.8 & 15.1 & 3.0 & 0.1 & 0.2 & 0.2 & 25.6 & 0.1 & 0.0 \\
\hline & 4 & 55.7 & 1.0 & 0.9 & 0.8 & 15.0 & 3.7 & 0.1 & 0.2 & 0.2 & 22.0 & 0.3 & 0.0 \\
\hline & 5 & 64.4 & 0.8 & 0.4 & 0.2 & 0.6 & 1.8 & 0.2 & 0.0 & 0.1 & 30.9 & 0.6 & 0.2 \\
\hline & 6 & 63.1 & 1.0 & 1.8 & 0.2 & 0.7 & 2.4 & 0.1 & 0.0 & 2.8 & 27.2 & 0.6 & 0.1 \\
\hline
\end{tabular}

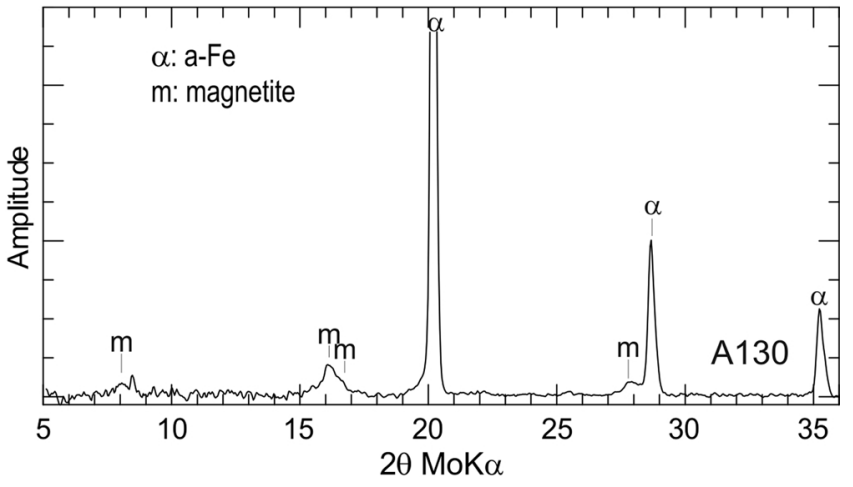

Fig. 10. $\mu \mathrm{XRD}$ patterns collected on the corrosion products of sample A261. The investigated zone corresponds to the dotted rectangle on the BSE image of Fig. 9. conditions in a geologic repository, but the abrupt changes in temperature due to breakdown of the heating system were not. Interestingly, the first breakdown between $t_{0}+708$ and 802 days did not seem to significantly impact $\mathrm{pH}$ or TIC values. In contrast, reheating correlated with a steady increase in TIC, $\left[\mathrm{SO}_{4}{ }^{2-}\right]$ and $\left[\mathrm{Cl}^{-}\right]$ and $\mathrm{pH}$, and with a decrease in $[\mathrm{Fe}]_{\mathrm{aq}}$. The evolution of anionic tracers $\left(\mathrm{Cl}^{-}\right.$and $\left.\mathrm{SO}_{4}{ }^{2-}\right)$ suggests changes in the water level in the test chamber, with salts precipitated at water low levels, and redissolved at higher levels [51,61]. During this period, and during increase in $\mathrm{pH}, \mathrm{Fe}$ could be slowly incorporated in solids, or get diluted by seeping solutions.

\subsection{Corrosion of $C$-steel under alkaline conditions}

All samples have relatively modest average rates of corrosion. They are also covered - mostly - by thin layers of CPs, sometimes enriched in $\mathrm{Si}$ or S. In addition to these general features, some samples display more corroded areas, made by depressions containing siderite, chukanovite, magnetite, and covered by bulges and tubercles of CPs. In some of these depressions, a layer of $\beta-\mathrm{Fe}_{2}(\mathrm{OH})_{3} \mathrm{Cl}$ formed in contact with steel. Although we did not observe fully developed layers of Fe sulfide, characterization of related coupons revealed the presence of such phases [62]. Finally, all coupon extremities are covered, at least partially, by ankerite or siderite particles, hinting at solution conditions in equilibrium with respect to siderite. None of the coupons exhibit the large damage observed in the previous study [51,52], confirming that such damage resulted from the physico-chemical transients during the experiment early stages (heating, resaturation of borehole walls, $\mathrm{pH}$ transient).

The almost negligible corrosion for Series 3-Rods 1-2 samples, combined with the presence of thin layers of CPs, suggest that the surface was significantly protected. Indeed, the observed average rate is below $1 \mu \mathrm{m} / \mathrm{a}$, significantly lower than the residual rate for iron in clay 
a

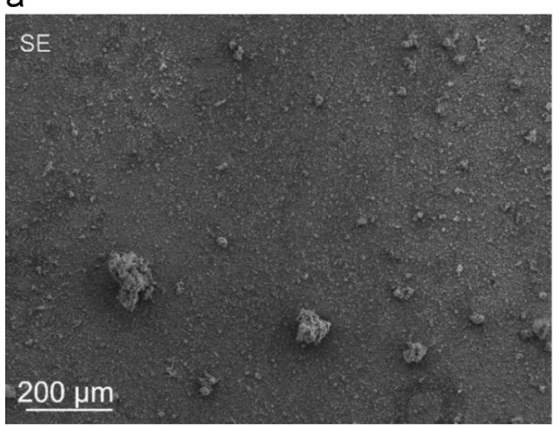

C
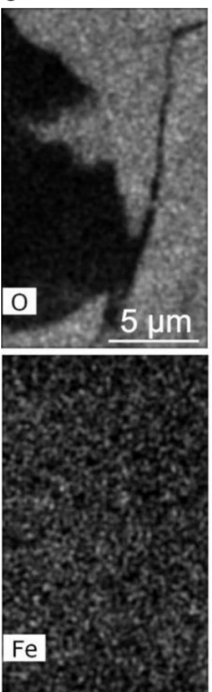

d
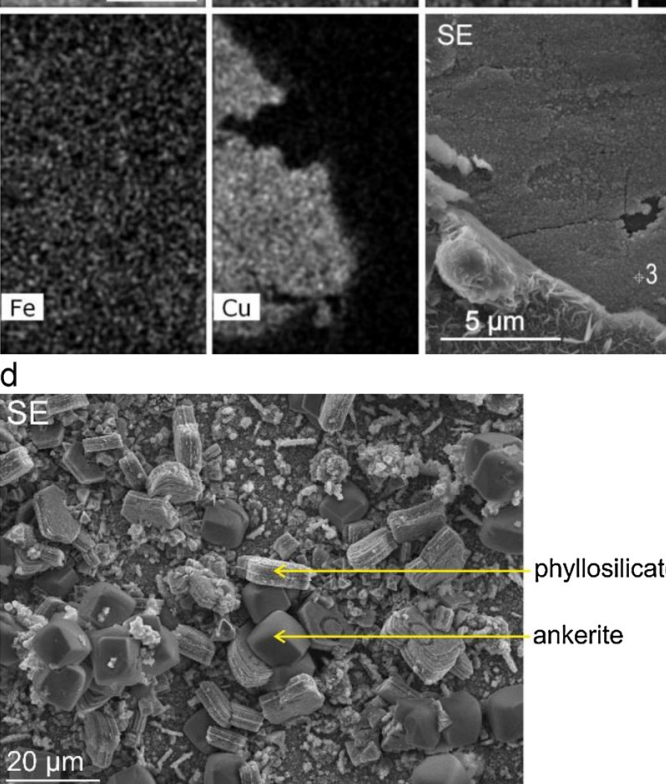

b
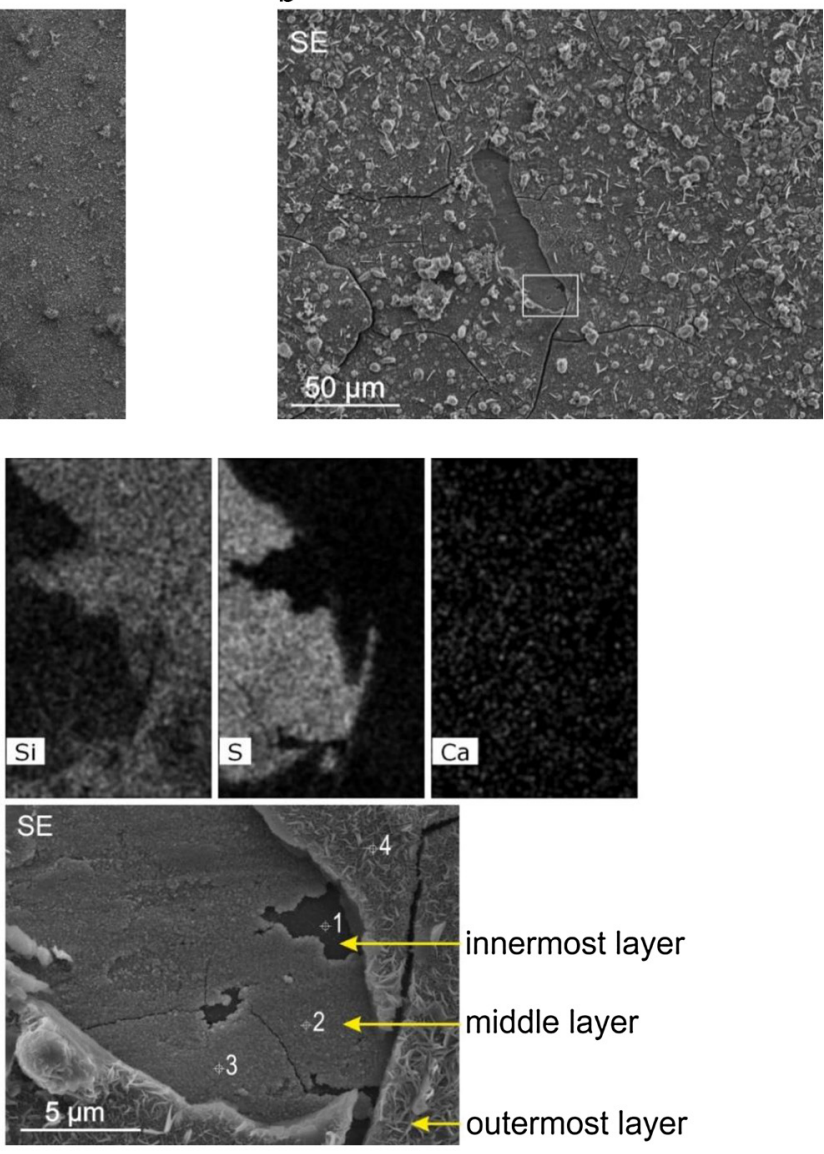

e

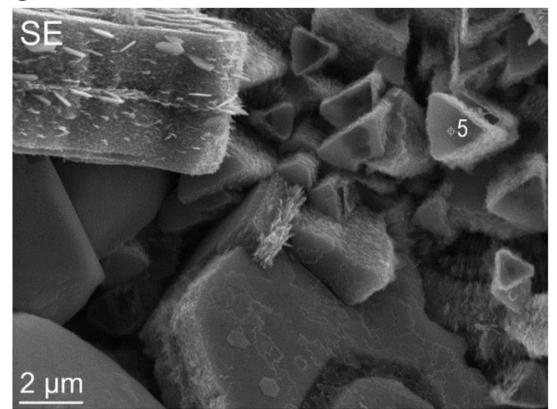

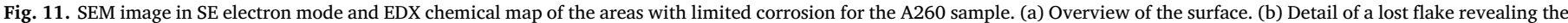

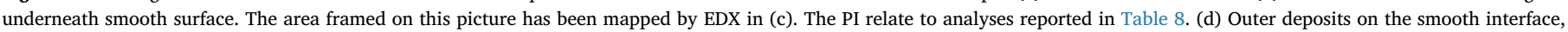

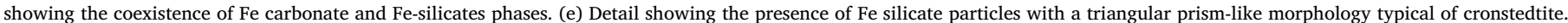

slurry (about $6 \mu \mathrm{m} / \mathrm{a}$; [63]). Surface protection may result from diffusion limitation of oxidized $\mathrm{Fe}$ and/or oxidizing species to the metal surface. A first possibility is that the entire corrosion interface provides such a limitation. In that case, however, more significant corrosion would be observed near cracks, of defects, which is not observed here. An alternate explanation is that the metal surface would be protected by a thin barrier layer a few nm thick, directly at the steel surface $[49,63,64]$. This layer controls the transport of Fe and O (or vacancies) by solid-state diffusion, with the cathodic reaction occurring at the outer surface of the barrier layer [65]. A clue to this location of the cathodic sites is the observation of a thin fringe of Cu-enriched CPs. Copper itself is present as a trace element in clay, but then its accumulation to significant concentrations in very limited areas right near the trace of C-steel original surface is noteworthy. Indeed, in previous studies of steel corrosion under anoxic conditions, $\mathrm{Cu}$ has been shown to reduce at cathodic sites, and form metal copper [66]. In the presence of dissolved sulfide, metal copper can reoxidize to form $\mathrm{CuS}_{2}$ at $25^{\circ} \mathrm{C}$
[67-69]. Our observation of $\mathrm{Cu}$ sulfide precipitates near the steel surface supports such a scenario of $\mathrm{Cu}$ reduction followed by conversion to sulfide. It also confirms that the cathodic reaction is located very close to the steel surface. Note however that inner layers of Fe silicate can be present between $\mathrm{C}$-steel and the $\mathrm{Cu}$ sulfide, suggesting either that these inner layers can protect the metal and conduce electrons. Another possibility is that $\mathrm{Cu}$ sulfide formed only during the corrosion initial stage, when no Fe silicate was present; these inner CPs then formed after the sulfide fringe.

In contrast, the heterogeneity in the corrosion damage for Series 3Rods 3-4 samples reveals that the whole surface is not protected, suggesting that anodic and cathodic sites are spatially separated. Interestingly, a similar heterogeneity in surface corrosion was observed for steel in contact with clay materials [14,70] or in seawater [71]. The surface dichotomy was linked to the formation of a differential aeration cell, with minerals such as Fe oxide and sulfide phases associated to cathodic reactions [71]. Here a similar process is observed, with thin Fe 

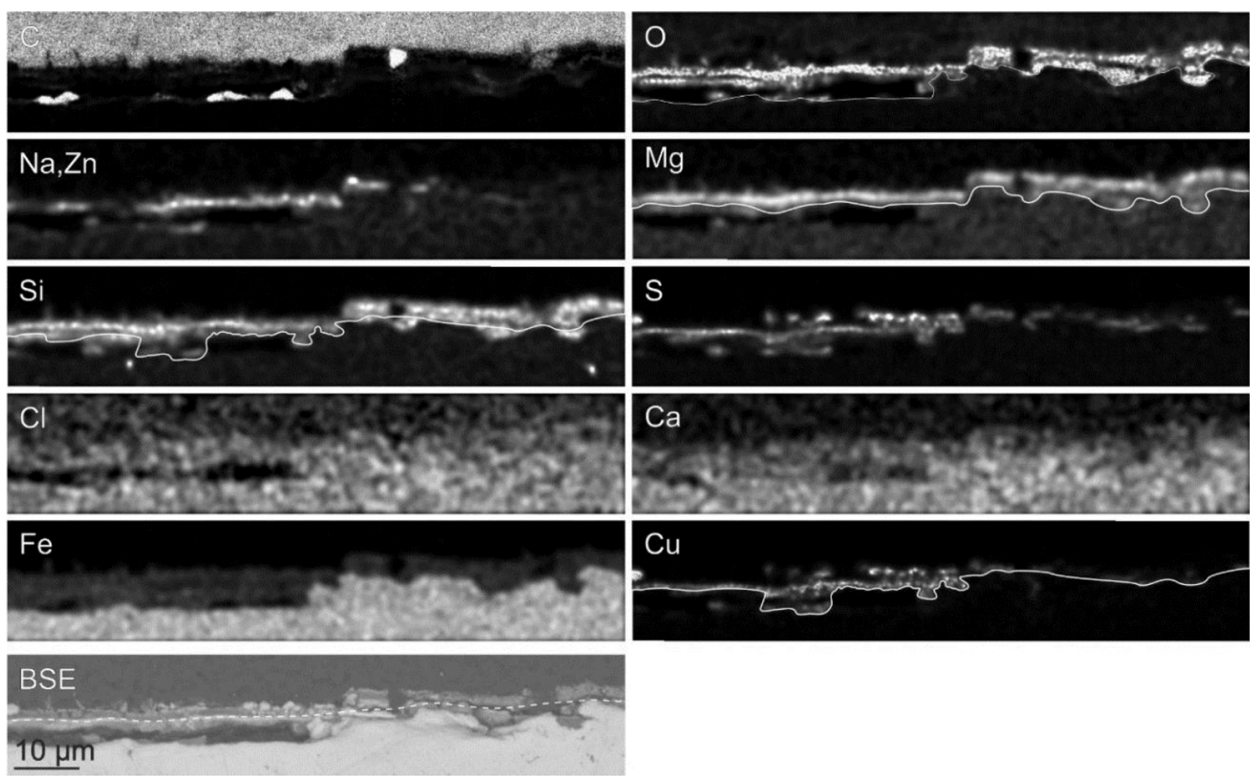

Fig. 12. SEM image in BSE mode and chemical maps of the cross of interface with limited corrosion for sample A260.

Table 8

Quantification of SEM-EDX analyses performed in areas of limited corrosion of the surface of the A260 coupon (reacted for 748 days at 85 and $25^{\circ} \mathrm{C}$ ). Points of Interest (PI) are indicated on Fig. 11.

\begin{tabular}{lllllllllllllll}
\hline \multirow{2}{*}{ PI } & \multicolumn{10}{c}{ Composition (at.\%) } \\
\cline { 2 - 12 } & $\mathrm{O}$ & $\mathrm{Na}$ & $\mathrm{Mg}$ & $\mathrm{Al}$ & $\mathrm{Si}$ & $\mathrm{S}$ & $\mathrm{Cl}$ & $\mathrm{K}$ & $\mathrm{Ca}$ & $\mathrm{Fe}$ & $\mathrm{Cu}$ & $\mathrm{Zn}$ \\
\hline 1 & 62.0 & 0.2 & 3.8 & $\mathrm{~nm}^{\mathrm{a}}$ & 13.7 & 1.0 & $\mathrm{~nm}$ & $\mathrm{~nm}$ & $\mathrm{~nm}$ & 19.0 & 0.3 & $\mathrm{~nm}$ \\
2 & 15.4 & 0.8 & 1.5 & $\mathrm{~nm}$ & 3.2 & 33.9 & $\mathrm{~nm}$ & $\mathrm{~nm}$ & $\mathrm{~nm}$ & 24.5 & 20.6 & $\mathrm{~nm}$ \\
3 & 13.0 & 0.6 & 1.0 & $\mathrm{~nm}$ & 3.1 & 36.3 & $\mathrm{~nm}$ & $\mathrm{~nm}$ & $\mathrm{~nm}$ & 24.6 & 21.4 & $\mathrm{~nm}$ \\
4 & 64.5 & 0.3 & 8.2 & $\mathrm{~nm}$ & 13.0 & 1.0 & $\mathrm{~nm}$ & $\mathrm{~nm}$ & $\mathrm{~nm}$ & 12.9 & 0.1 & $\mathrm{~nm}$ \\
5 & 68.2 & 0.9 & 0.5 & $\mathrm{~nm}$ & 6.1 & 1.6 & $\mathrm{~nm}$ & $\mathrm{~nm}$ & $\mathrm{~nm}$ & 22.6 & $\mathrm{~nm}$ & $\mathrm{~nm}$ \\
\hline
\end{tabular}

${ }^{\mathrm{a}} \mathrm{nm}=$ not measured.

Table 9

Quantification of SEM-EDX analyses at the extensively corroded interface of sample A260 (reacted for 748 days at 85 and $25^{\circ} \mathrm{C}$ ). Points of Interest (PI) are indicated on Fig. 13.

\begin{tabular}{|c|c|c|c|c|c|c|c|c|c|c|c|c|}
\hline \multirow[t]{2}{*}{ PI } & \multicolumn{12}{|c|}{ Composition (at.\%) } \\
\hline & $\mathrm{O}$ & $\mathrm{Na}$ & $\mathrm{Mg}$ & $\mathrm{Al}$ & $\mathrm{Si}$ & $\mathrm{S}$ & $\mathrm{Cl}$ & $\mathrm{K}$ & $\mathrm{Ca}$ & $\mathrm{Fe}$ & $\mathrm{Cu}$ & $\mathrm{Zn}$ \\
\hline 1 & 59.1 & 0.1 & 0.1 & 0.2 & 0.3 & 0.6 & 0.2 & 0.0 & 0.0 & 39.2 & 0.2 & 0.1 \\
\hline 2 & 58.9 & 0.1 & 0.1 & 0.4 & 0.4 & 0.5 & 2.6 & 0.0 & 0.0 & 36.8 & 0.1 & 0.0 \\
\hline 3 & 63.8 & 0.3 & 0.4 & 0.3 & 0.2 & 0.3 & 0.0 & 0.0 & 0.0 & 34.1 & 0.4 & 0.1 \\
\hline 4 & 71.3 & 0.2 & 0.3 & 0.3 & 0.3 & 1.7 & 0.1 & 0.0 & 0.0 & 25.3 & 0.4 & 0.1 \\
\hline 5 & 69.7 & 0.2 & 0.2 & 0.3 & 0.8 & 1.6 & 0.2 & 0.0 & 0.0 & 26.5 & 0.3 & 0.1 \\
\hline 6 & 74.3 & 0.2 & 0.2 & 0.1 & 0.2 & 0.5 & 0.0 & 0.0 & 0.0 & 24.0 & 0.3 & 0.1 \\
\hline 7 & 74.8 & 0.2 & 0.3 & 0.2 & 0.2 & 0.5 & 0.0 & 0.0 & 0.0 & 23.3 & 0.3 & 0.1 \\
\hline 8 & 64.0 & 0.2 & 0.3 & 0.3 & 0.8 & 0.4 & 0.0 & 0.0 & 0.0 & 33.5 & 0.5 & 0.1 \\
\hline 9 & 64.0 & 0.4 & 0.3 & 0.2 & 0.6 & 0.2 & 0.0 & 0.0 & 0.0 & 33.9 & 0.3 & 0.1 \\
\hline 10 & 69.2 & 0.2 & 0.7 & 0.1 & 4.7 & 0.1 & 0.0 & 0.0 & 0.0 & 24.7 & 0.1 & 0.0 \\
\hline 11 & 76.7 & 0.2 & 0.3 & 0.2 & 0.1 & 0.2 & 0.0 & 0.0 & 0.0 & 21.8 & 0.3 & 0.1 \\
\hline 12 & 77.5 & 0.3 & 0.3 & 0.2 & 0.1 & 0.2 & 0.0 & 0.0 & 0.0 & 20.9 & 0.4 & 0.1 \\
\hline 13 & 66.5 & 0.5 & 1.3 & 0.2 & 8.3 & 0.0 & 0.0 & 0.0 & 0.0 & 22.8 & 0.3 & 0.1 \\
\hline 14 & 61.5 & 0.1 & 1.3 & 0.1 & 9.8 & 0.0 & 0.1 & 0.0 & 0.0 & 27.1 & 0.0 & 0.0 \\
\hline 15 & 61.6 & 0.2 & 1.3 & 0.1 & 6.5 & 0.1 & 0.1 & 0.0 & 0.0 & 29.7 & 0.2 & 0.1 \\
\hline
\end{tabular}

silicate and $(\mathrm{Fe}, \mathrm{Cu})$ sulfide layers acting as surface electron-conducing phases on large cathodic areas. Sulfides are good electron (semi)-conducers, and, as explained above, the presence of $\mathrm{Cu}$ sulfide can be traced to the occurrence of cathodic reactions near the metal surface. The electron conductivity of Fe phyllosilicates is not well known, but these solids did not charge during SEM observations. The case for spatially separated anodic and cathodic reactions is further supported by the formation of $\beta-\mathrm{Fe}_{2}(\mathrm{OH})_{3} \mathrm{Cl}$ near the steel-CPs interface. This solid phase has been previously observed for samples corroded in marine environments [72], in soils permanently immersed in slightly diluted $\mathrm{NaCl}$ waters [40,73,74], and for extensively corroded Series 1 samples [52]. At $25^{\circ} \mathrm{C}$, this solid is actually stable only at rather high $\mathrm{Cl}^{-}$and $\mathrm{Fe}$ (II) concentrations [75], and so its presence in the corrosion layers in a somewhat diluted aquifer implies electrophoretic accumulation of $\mathrm{Cl}^{-}$. Such a mechanism can operate only if anodic and cathodic reactions are (at least partially) spatially separated. Finally, the sharp limit between areas of limited and extended corrosion, shape of the depression profiles near these limits and he steep slopes of the depression edges [76] are additional evidence for spatial separation of anodic and cathodic sites.

The initiation of such pits is usually related to galvanic coupling between areas more or less exposed to $\mathrm{O}_{2}$ in (sub)oxic conditions [70,71]. Areas easily accessed by $\mathrm{O}_{2}$ become cathodic, whereas those less exposed to $\mathrm{O}_{2}$ (e.g. more protected by CPs) may become anodic. The galvanic coupling is sustained by the precipitation of CPs in areas of extended corrosion, further shielding the surface from $\mathrm{O}_{2}$ diffusion. The driving force for such a reaction cell is the large difference in electrochemical potential between $\mathrm{O}_{2}$ reduction and $\mathrm{Fe}$ oxidation. Interestingly, such coupling is observed only for coupons corroded at room temperature. The major impacts of the low $\mathrm{T}$ transients would be (1) metal oxidation occurring more rapidly than precipitation of CPs [77,78], (2) development of microbial communities, responsible for the formation of biofilms or of Fe sulfide, and (3) partial loss of air tightness.

The formation of a galvanic cell can be favoured by the accumulation of microorganisms and biofilms shielding fractions of the surface from oxidant, thus differentiating anodic and cathodic areas [71]. Here, however, the major oxidant (water) is expected to be present everywhere. In contrast, sulfide can locally initiate cathodic reactions. Another possibility is that slits from the sample holder act as pseudocavities, initially preventing diffusion of $\mathrm{OH}^{-}$in areas affected by corrosion. At room temperature, under conditions where metal oxidation is faster than precipitation for CPs $[77,78]$, this would result in a locally faster damage, and the initiation of an anodic area. Afterwards, upon increase in temperature, precipitation of CPs would speed up. Yet, precipitation and diffusion would be thwarted in the confined areas within the slit, effectively hindering corrosion. Finally, suboxic episodes may have occurred and provide conditions favouring the formation of differential aeration cells, with areas easily accessed by $\mathrm{O}$ acting as 

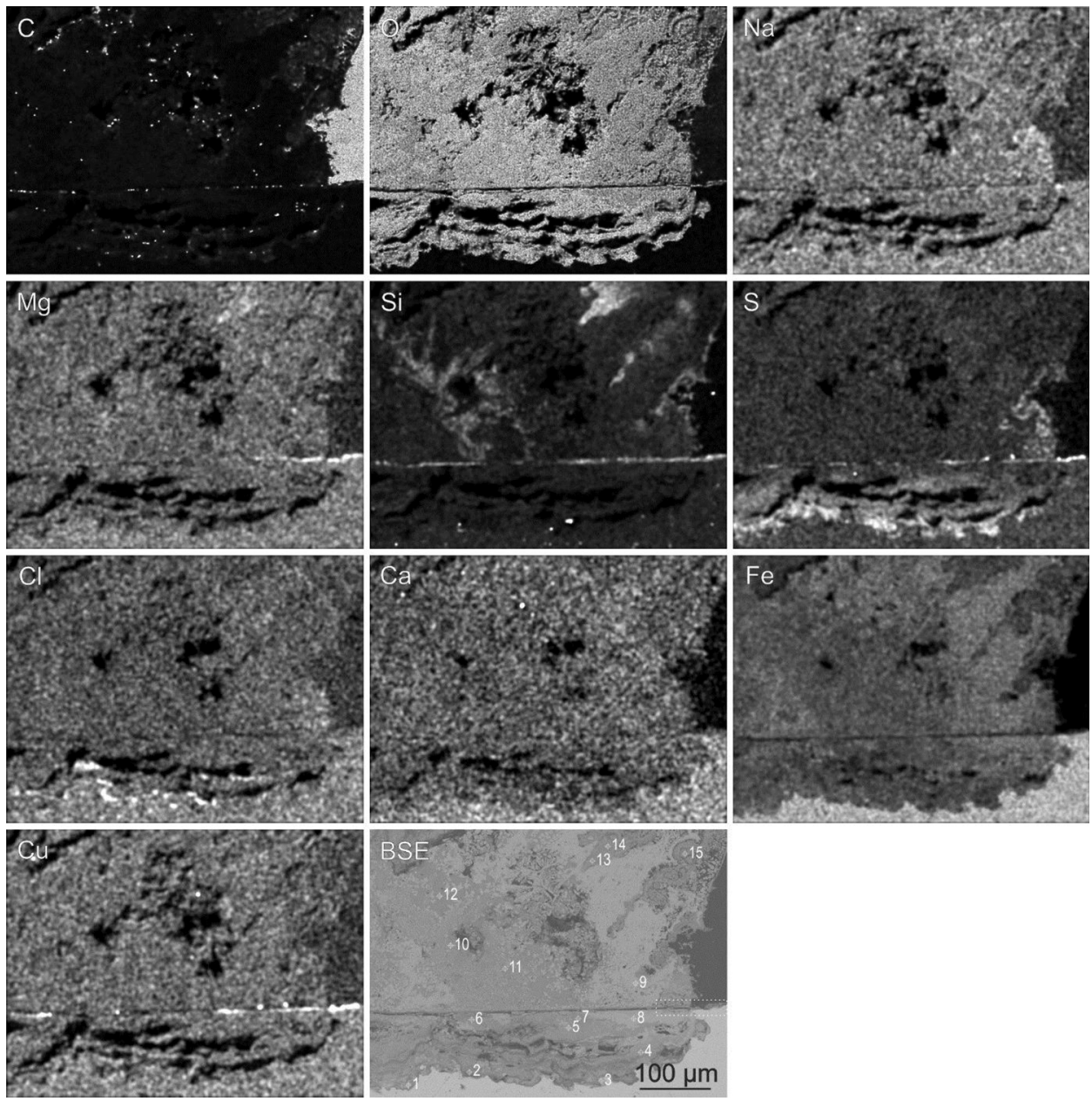

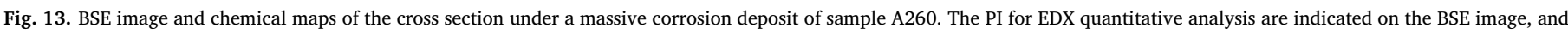
quantitative results are given in Table 9.

cathodic sites, and corrosion depressions filled with CPs acting as anodic sites. Under consistent suboxic conditions, however, precipitation of Fe(III)-containing (hydr)oxides would have been expected [70]. Such Fe(III) (hydr)oxides were not observed, either because they were reduced afterwards, or, because very little $\mathrm{O}_{2}$ actually entered into the test chamber.

Once initiated, the differential oxidation cell can operate only if electron will spontaneously flow from the anodic to the cathodic sites. In anoxic aqueous conditions, possible reductants are $\mathrm{H}_{2} \mathrm{O}$ or $\mathrm{H}_{2} \mathrm{~S}$. Water is expected to be always in unlimited supply, and so it may act as the main oxidant in our experiment. However, the difference in electrochemical potential favouring steel oxidation and $\mathrm{H}_{2} \mathrm{O}$ reduction can be affected by local $\mathrm{pH}$ values, which are themselves related to local electrochemical reactions. For example, under slightly alkaline conditions, oxidation of iron may be written as

$\mathrm{Fe}(0) \rightarrow \mathrm{Fe}^{2+}+2 \mathrm{e}^{-}$

The oxidoreduction potential associated to this reaction is given by the Nernst equation, and equals

$E=E_{F e / F e 2+}^{o}+\frac{R T}{2 F} \operatorname{Ln}\left(F^{2+}\right)$,

where $\mathrm{E}_{\mathrm{Fe} / \mathrm{Fe} 2+}^{\mathrm{i}}$ is the standard electrochemical potential for iron oxidation, $\mathrm{R}$ is the gas constant, $\mathrm{T}$ is temperature, $\mathrm{F}$ is the Faraday constant, and $\left|\mathrm{Fe}^{2+}\right|$ is the $\mathrm{Fe}^{2+}$ activity in solution. At alkaline $\mathrm{pH} \mathrm{Fe} \mathrm{F}^{2+}$ can precipitate to form $\mathrm{Fe}(\mathrm{OH})_{2}$ (s), according to

$\mathrm{Fe}^{2+}+2 \mathrm{H}_{2} \mathrm{O} \rightarrow \mathrm{Fe}(\mathrm{OH})_{2}(\mathrm{~s})+2 \mathrm{H}^{+}$ with $\log _{10} \mathrm{~K}=-12.95$ [79]. Eqs. (3) and (5) can be combined to write the reaction of direct $\mathrm{Fe}$ oxidation to $\mathrm{Fe}(\mathrm{OH})_{2}(\mathrm{~s})$, according to

$\mathrm{Fe}(0)+2 \mathrm{H}_{2} \mathrm{O} \rightarrow \mathrm{Fe}(\mathrm{OH})_{2}(\mathrm{~s})+2 \mathrm{H}^{+}+2 \mathrm{e}^{-}$

The electrochemical potential for this oxidation reaction can be calculated by using the Nernst relationship and the $\mathrm{Fe}(\mathrm{OH})_{2}(\mathrm{~s})$ solubility, resulting in

$E=E_{\mathrm{Fe} / \mathrm{Fe}(\mathrm{OH}) 2(s)}^{o}+\frac{R T}{2 F} \operatorname{Ln}\left(\left(H^{+}\right)^{2}\right)$.

At $25^{\circ} \mathrm{C}$, this relationship for the potential at the anodic site is simplified to

$E_{\text {anod }}=E_{\mathrm{Fe} / \mathrm{Fe}(\mathrm{OH}) 2(\mathrm{~s})}^{\mathrm{o}}-0.059 \mathrm{p} \mathrm{H}_{\text {anod }}$,

with $E_{\mathrm{Fe} / \mathrm{Fe}(\mathrm{OH}) 2(\mathrm{~s})}^{O}=-0.0585 \mathrm{~V}$ and $\mathrm{pH}_{\text {anod }}$ is the $\mathrm{pH}$ value at the anodic site. This electrochemical potential for $\mathrm{Fe}(0)$ can be compared to the oxidoreduction potential for $\mathrm{H}_{2} \mathrm{O}$ reduction, which is given by

$\mathrm{E}=\mathrm{E}_{\mathrm{H}+\mathrm{H} 2}^{\mathrm{o}}+\frac{\mathrm{RT}}{\mathrm{F}} \operatorname{Ln} \frac{\left(H^{+}\right)}{\left(\mathrm{H}_{2}\right)}$,

with $\mathrm{E}_{\mathrm{H}+/ \mathrm{H}^{2}}^{O}=0 \mathrm{~V}$ by convention. The $\left(\mathrm{H}_{2}\right)$ gas activity can be related to $\mathrm{P}_{\mathrm{H} 2}$, and so at $25^{\circ} \mathrm{C}$ :

$E_{\text {cath }}=-0.059 \mathrm{pH}_{\text {cath }}-0.059 \log _{10}\left(P_{H 2} / P o\right)$

For the corrosion reaction to occur (and neglecting any overpotential), $E_{\text {cath }}$ must be greater than $E_{\text {anod }}[80]$, and so the following inequality must be obeyed 


\section{a. point a}

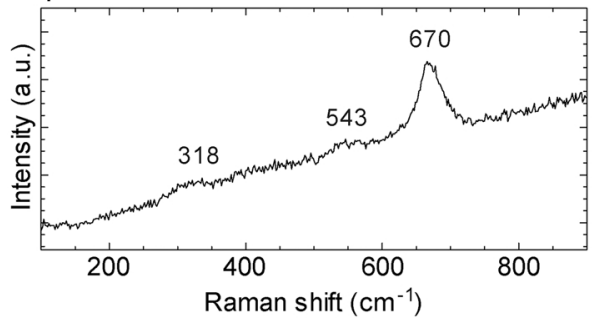

c. point C

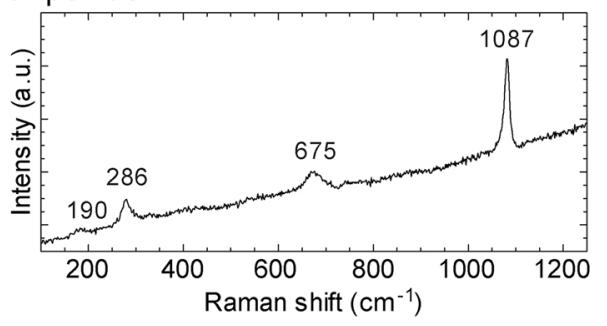

e.

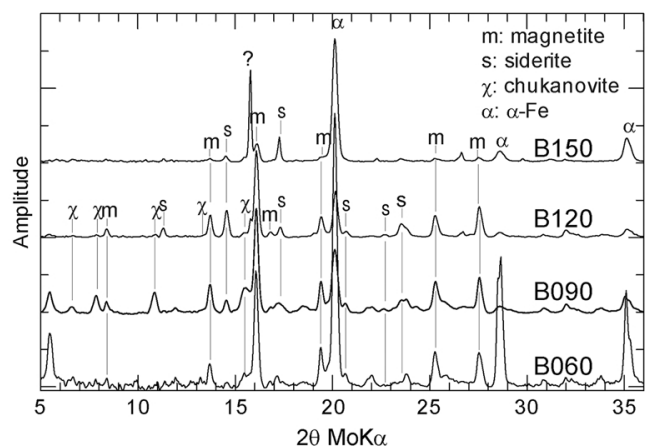

b.

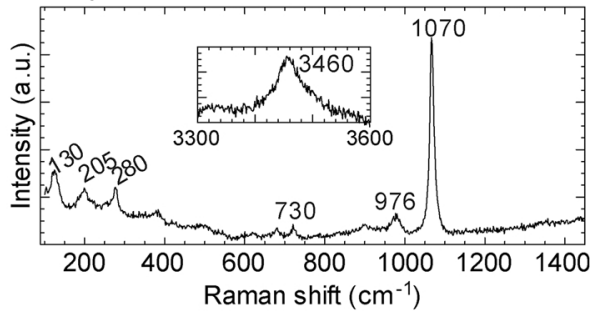

d. point d

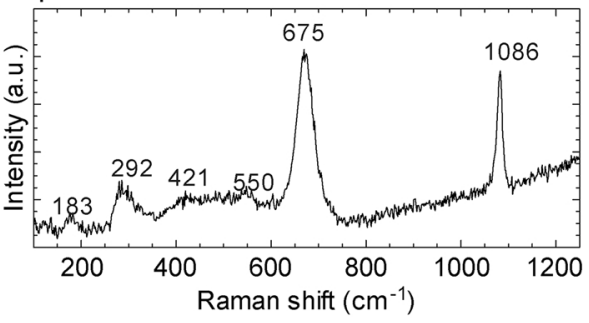

f.

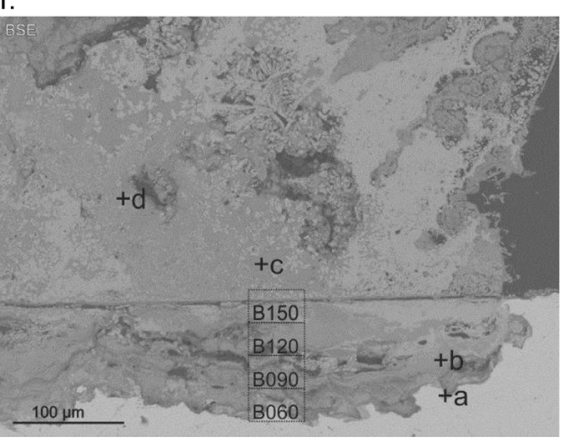

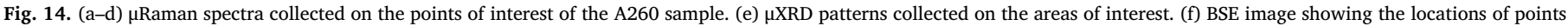
and areas probed by $\mu \mathrm{RS}$ and $\mu \mathrm{DRX}$, respectively.

$p H_{\text {anod }}-p H_{\text {cath }}>\frac{E_{\mathrm{Fe} / \mathrm{Fe}(\mathrm{OH}) 2(s)}^{o}}{0.059}+\log _{10}\left(P_{\mathrm{H} 2} / P_{o}\right)$

Equation shows that for $\mathrm{P}_{\mathrm{H} 2}=\mathrm{P}_{0}$, the difference is extremely limited. For $\mathrm{P}_{\mathrm{H} 2}$ below 0.01 atm (corresponding to the measured $\mathrm{P}_{\mathrm{H} 2}$ in the test chamber), $\mathrm{pH}_{\text {cath }}-\mathrm{pH}_{\text {anod }}$ must be smaller than 3 . Thus, this simple calculation indicates that for $\mathrm{pH}_{\text {cath }}$ values greater than $9, \mathrm{pH}_{\text {anod }}$ must be greater than 6 . These mild $\mathrm{pH}$ conditions are confirmed by the nature of CPs in areas of extended corrosion, i.e. siderite, chukanovite, $\beta-\mathrm{Fe}_{2}(\mathrm{OH})_{3} \mathrm{Cl}$, which are all unstable under acidic conditions [81]. Thus, alkaline conditions seem to be somewhat maintained in these areas, meaning that the local production of $\mathrm{H}^{+}$is balanced by a flux of $\mathrm{OH}^{-}$from the solution. In fact, an indirect evidence for such an anionic flux comes from the formation of $\beta-\mathrm{Fe}_{2}(\mathrm{OH})_{3} \mathrm{Cl}$, which can be explained only by electrophoretic concentration of $\mathrm{Cl}^{-}$near the metal surface [11,52]. Likewise, $\mathrm{OH}^{-}$would be locally accumulated by electrophoresis (but not $\mathrm{Si}(\mathrm{OH})_{4}$, the neutral predominant form of silicate at $\mathrm{pH} \leq 9$; [82]). The concentration of $\mathrm{OH}^{-}$in the test chamber can be estimated from the dissociation constant of water at $\mathrm{T}=85^{\circ} \mathrm{C}$ $\left(\mathrm{K}_{\mathrm{w}}=10^{-12.5}\right.$; [83]), and, for $\mathrm{pH}$ values between 7.2 and 9.4 , ranges from $10^{-(12.4-7.2)}$ to $10^{-(12.4-9.4)} \mathrm{M}$, i.e. $10^{-5}$ to $10^{-3} \mathrm{M}$. The upper limit of this range is about 40 times lower than $\left[\mathrm{Cl}^{-}\right]_{\mathrm{aq}}$ and so a substantial amount of $\mathrm{OH}^{-}$can still accumulate near the metal surface. In conclusion, the initiation of galvanic coupling in our study is likely related to the faster corrosion rate at room temperature, possibly coupled with the local shielding of the coupon surface by biofilms or by the sample holder and by limited ingress of $\mathrm{O}_{2}$.

The isovolumic replacement of metal by CPs implies that a significant fraction of oxidized Fe migrated from the steel-CPs interface to the coupon surface, where it readily precipitates. The solids present in the outer CPs are similar to the inner CPs, and in addition they contain Fe sulfide and Fe silicate. The presence of Fe silicate in the outer CPs was observed for Series 1 coupons reacted over long corrosion times (up to $t_{0}+923$ days). At the recovery time of these previous samples, physico-chemical conditions in the test chamber were already similar to those observed for the Series 3-Rods 3-4 (i.e. near-neutral $\mathrm{pH}$ values). Such conditions favor the formation of Fe silicate and magnetite directly in the outer CPs units. This precipitation would then scavenge $\mathrm{Si}$ out of the porewater diffusing the $\mathrm{CPs}$, preventing it from reaching the inner CPs.

\subsection{On the nature and significance of sulfide minerals}

As for Series 1 coupons, sulfide minerals were observed near the trace of the original surface for Series 2 and Series 3 coupons partially reacted at room temperature. However, in Series 1 coupons, Fe sulfide formed a thin fringe of elongated particles radiating outward of the original surface [52]. The morphology of these particles, and their formation during the early experimental stage, suggested that they resulted from the activity of sulfidogenic prokaryotes. Here these sulfide are present as compact layers embedded between two thin bands of $\mathrm{Fe}$ silica, and they are somewhat enriched in $\mathrm{Cu}$ and $\mathrm{Zn}$, which seem to rule out direct participation from sulfidogenic prokaryotes (especially for $\mathrm{Cu}$, which can poison microorganisms; [84]). Instead, sulfide could have been supplied by remotely located SRP or by reduction of pyrite from the clay formation. The precipitation of $\mathrm{Cu}$ sulfide could then 

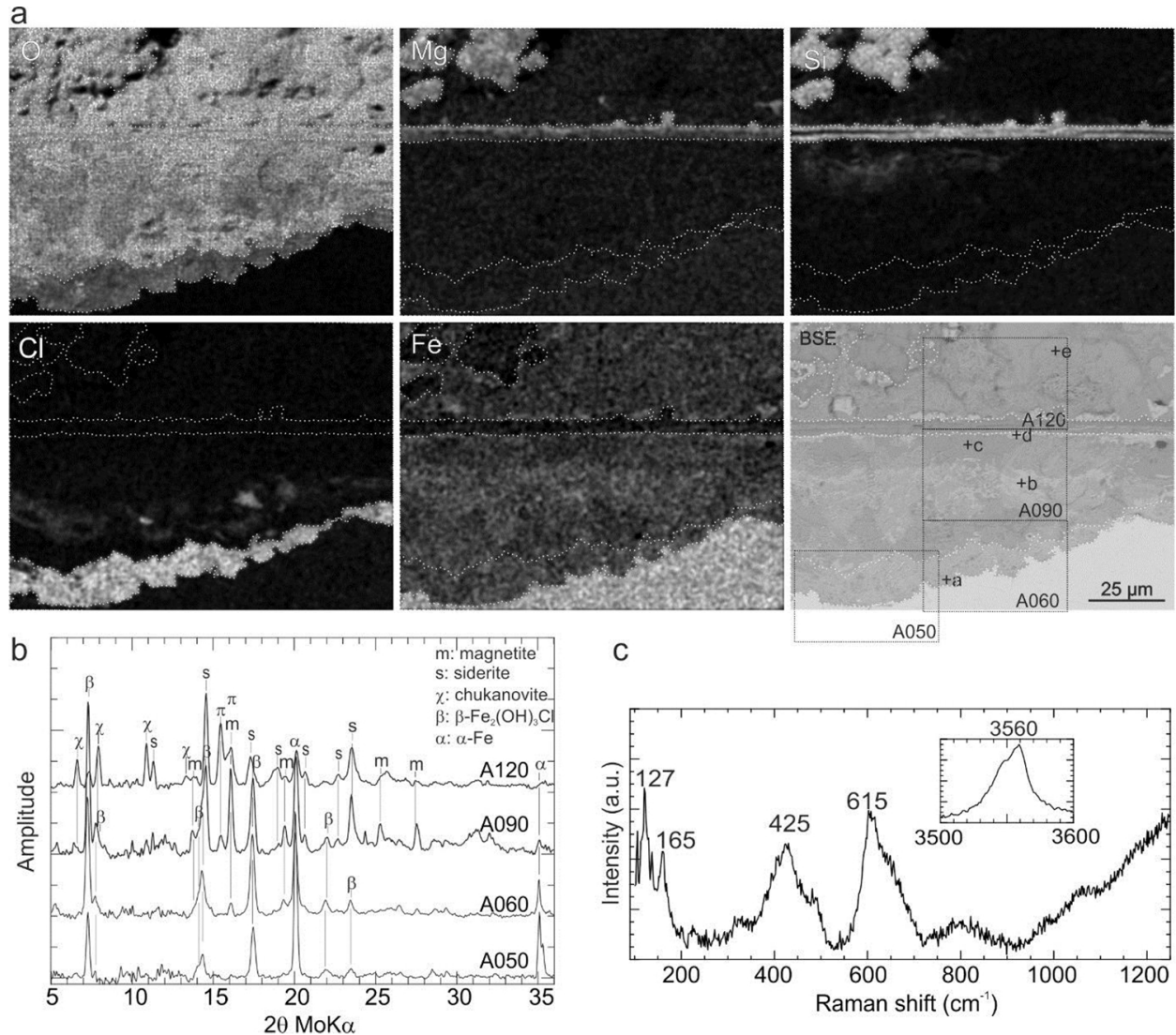

C
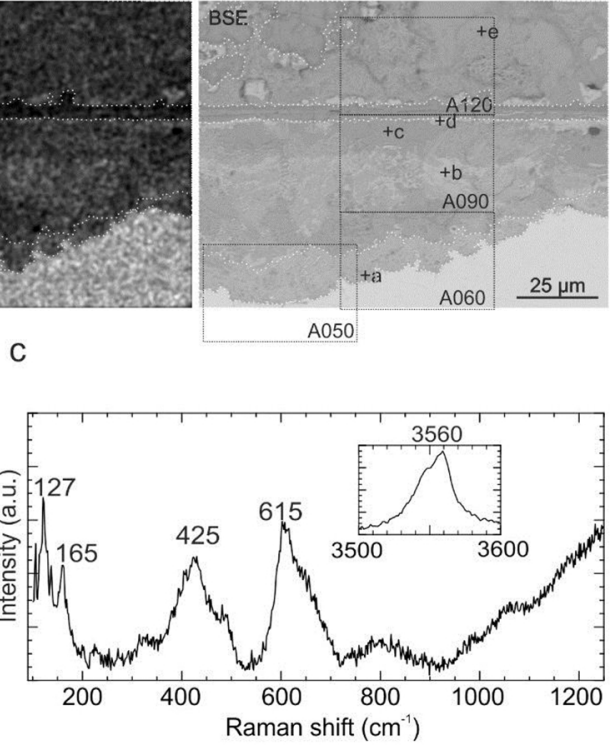

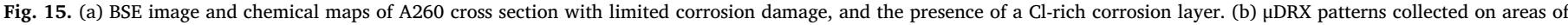
interest (indicated on the BSE image of the interface). (c) Example of Raman spectrum collected on the Cl-rich layer, and corresponding to $\beta$-Fe ${ }_{2}(\mathrm{OH})_{3} \mathrm{Cl}$.

occur by the two-step mechanism of $\mathrm{Cu}$ reduction, followed by conversion to sulfide solid, as explained above. During the conversion from metal to sulfide, additional elements such as $\mathrm{Zn}$ may coprecipitate with $\mathrm{Cu}$, a consequence of the low solubility of $\mathrm{Cu}$ and $\mathrm{Zn}$ sulfide [85]. Note that Fe sulfide were also detected in the inner and outer CPs of samples reacted for a significant period of time, whether after a $\mathrm{pH}$ transient, or only under alkaline $\mathrm{pH}$ conditions (this study). In cathodic areas, this sulfide layer can act as a cathodic surface when the external silicate layer is lost by flaking.

\subsection{Microbial activity and corrosion processes}

Microbiological characterizations of this study demonstrate that living micro-organisms, especially thermophilic SRP, were present on coupon surfaces and in the seeping porewater of the test chamber. The comparison of molecular biology, epifluorescence counting and MPN results reveals that many of these organisms could not be cultivated in standard media. This is the case when symbiotic relationships develop between strains, but cannot be reproduced by culture media [86].

One point which is to be clarified is the real impact of microbial activity on the observed corrosion processes. The MPN analysis and accumulation of sulfides in the seeping porewater are strong supporters of significant bioactivity during the low-temperature experimental periods $\left(\sim 30-25^{\circ} \mathrm{C}\right)$. In fact, it is possible that biofilms developed heterogeneously at the metal surface of Series 3-Rods 3-4 coupons during the low-temperature episodes, setting up galvanic coupling. However, the MPN procedure failed to reveal any significant bioactivity at temperatures higher than $70^{\circ} \mathrm{C}$. Again, it is quite possible that microorganisms would thrive in the test chamber under these conditions, but not in the cultures broths used for enumeration. Note however, that a

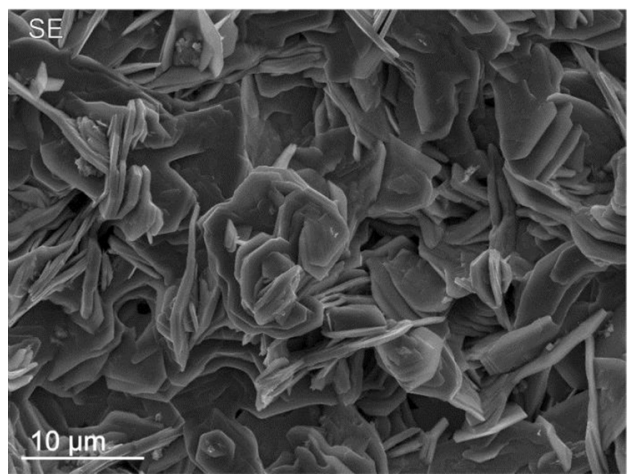

b

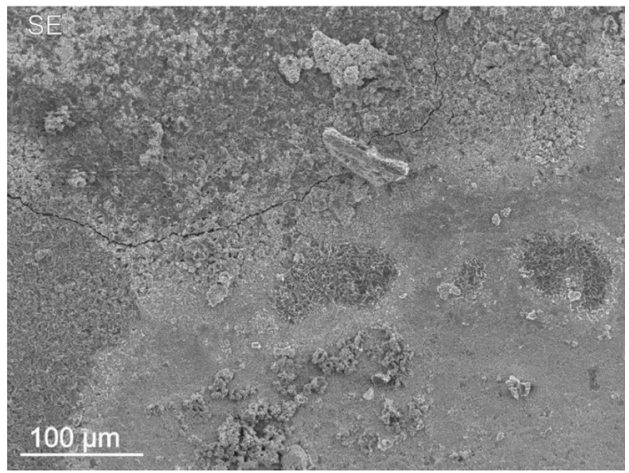

Fig. 16. (a) SE image of siderite particles near the coupon extremities of sample A260. (b) Overall view of the coupon extremities showing the siderite deposits. 

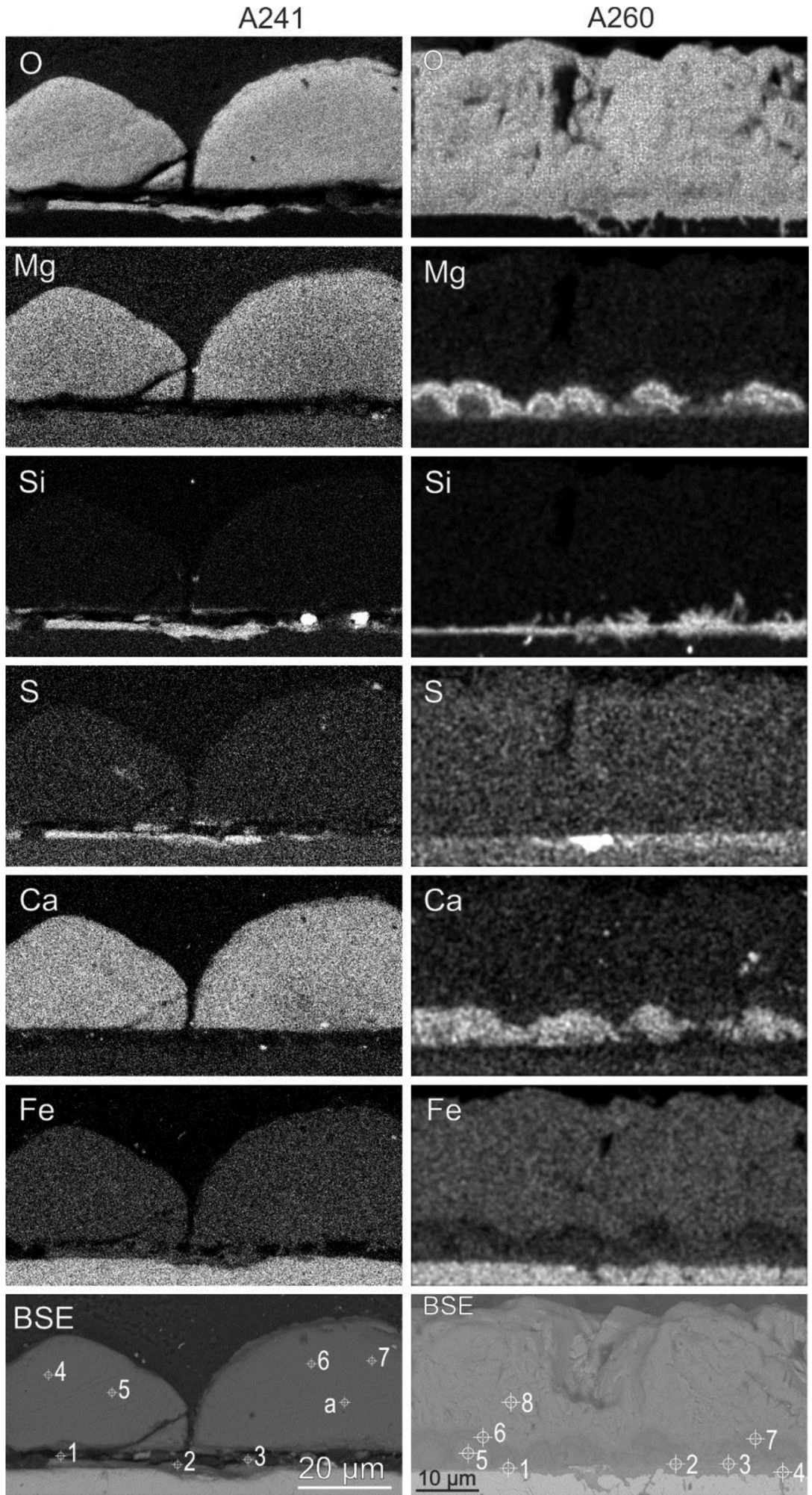

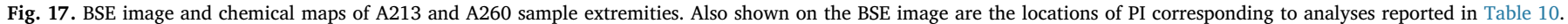

even in the absence of bioactivity at $70{ }^{\circ} \mathrm{C}$, the galvanic coupling would continue to operate provided anodic and cathodic areas are well separated and chemically distinct. Yet, with time, the anodic area laterally expands, covering previous cathodic surfaces. However, cathodic reactions can also take place at cementite particles, eventually keeping spatial separation between anodic and cathodic sites.

\subsection{Implication for nuclear waste disposal}

Despite relatively stable and alkaline $\mathrm{pH}$ conditions, a heterogeneous corrosion interface can form after two years of exposure to the test chamber. The average corrosion damage in itself is quite limited ( $20 \mu \mathrm{m}$ in 2 years). However, the separation between cathodic zones over a large surface fraction and anodic zones in corroded cavities implies that corrosion, once initiated, proceeds at a fairly constant rate, 
Table 10

Quantification of SEM-EDX analyses for corrosion products at the extremities of samples A241 and A260 (reacted at 85 and $25^{\circ} \mathrm{C}$ for 104 and 748 days, respectively). Points of Interest (PI) are indicated on Fig. 17.

\begin{tabular}{lllllllllllllll}
\hline Sample & PI & & & \multicolumn{1}{c}{ Composition (at.\%) } & & & & \\
& & & $\mathrm{O}$ & $\mathrm{Na}$ & $\mathrm{Mg}$ & $\mathrm{Al}$ & $\mathrm{Si}$ & $\mathrm{S}$ & $\mathrm{Cl}$ & $\mathrm{K}$ & $\mathrm{Ca}$ & $\mathrm{Fe}$ & $\mathrm{Cu}$ & $\mathrm{Zn}$ \\
\hline \multirow{2}{*}{$\mathrm{A} 241$} & 1 & 64.7 & 0.6 & 0.6 & 0.2 & 10.4 & 5.4 & 0.3 & 0.1 & 0.2 & 16.8 & 0.7 & 0.2 \\
& 2 & 70.2 & 0.5 & 0.5 & 0.3 & 12.6 & 1.5 & 0.1 & 0.0 & 0.4 & 13.2 & 0.6 & 0.2 \\
& 3 & 64.8 & 0.6 & 0.6 & 0.3 & 9.8 & 6.0 & 0.2 & 0.0 & 0.2 & 16.4 & 0.8 & 0.2 \\
& 4 & 76.2 & 0.3 & 2.7 & 0.1 & 0.1 & 0.0 & 0.0 & 0.0 & 7.4 & 12.6 & 0.4 & 0.1 \\
& 5 & 73.5 & 0.3 & 2.7 & 0.1 & 0.1 & 0.7 & 0.0 & 0.0 & 6.0 & 16.1 & 0.3 & 0.1 \\
& 6 & 74.7 & 0.3 & 2.7 & 0.1 & 0.1 & 0.0 & 0.0 & 0.0 & 7.4 & 14.2 & 0.3 & 0.1 \\
$\mathrm{~A} 260$ & 7 & 74.5 & 0.3 & 2.6 & 0.1 & 0.1 & 0.0 & 0.0 & 0.0 & 7.9 & 14.1 & 0.3 & 0.1 \\
& 1 & 65.4 & 0.2 & 1.6 & 0.2 & 14.6 & 1.1 & 0.1 & 0.1 & 0.1 & 16.4 & 0.2 & 0.0 \\
& 2 & 64.3 & 0.1 & 2.1 & 0.2 & 14.8 & 1.6 & 0.1 & 0.0 & 0.1 & 15.9 & 0.6 & 0.2 \\
& 3 & 67.5 & 0.2 & 1.5 & 0.3 & 13.6 & 1.7 & 0.1 & 0.0 & 0.1 & 14.1 & 0.9 & 0.1 \\
& 4 & 69.6 & 0.2 & 0.7 & 0.2 & 12.2 & 1.3 & 0.1 & 0.0 & 0.0 & 15.1 & 0.5 & 0.1 \\
& 5 & 74.7 & 0.5 & 3.8 & 0.1 & 0.1 & 0.0 & 0.0 & 0.0 & 4.7 & 15.8 & 0.2 & 0.0 \\
& 6 & 73.8 & 0.4 & 9.1 & 0.1 & 0.1 & 0.0 & 0.0 & 0.0 & 4.1 & 12.2 & 0.2 & 0.0 \\
& 7 & 74.7 & 0.4 & 8.6 & 0.1 & 0.1 & 0.0 & 0.0 & 0.0 & 3.4 & 12.2 & 0.3 & 0.1 \\
& 8 & 78.2 & 0.4 & 0.3 & 0.2 & 0.1 & 0.1 & 0.0 & 0.0 & 0.0 & 20.0 & 0.4 & 0.1 \\
\hline
\end{tabular}

even at alkaline $\mathrm{pH}$. Indeed, under these conditions, the rate seems to be controlled by the cathodic reaction of water reduction at the metal/ electrolyte interface. In the open conditions experienced by the coupons, water is readily available for such a reaction, which would result in rather sustained corrosion rates. In contrast, water flow toward the bottom of significantly damaged areas would be relatively hindered, thus preserving galvanic coupling.

This study also would suggest that under constant, well-controlled temperature conditions, C-steel surface may be protected by a uniform layer and possibly by a interfacial barrier layer. However, care should be exercised when extrapolating the results from these well-prepared steel surfaces to rougher industrial surfaces which will be likely marked by several defects. Such defects would act as initiation sites for the setup of galvanic coupling. Hence, the possibility of having relatively localized corrosion should not be overlooked.

\section{Conclusions}

In the course of this study, $\mathrm{pH}$ remained at slightly alkaline conditions in the test chamber of the MCO-Gravimetry experiment. As expected, these conditions resulted in limited corrosion at $85^{\circ} \mathrm{C}$ over two years. However, slightly more important corrosion was observed for samples exposed to $25^{\circ} \mathrm{C}$ episodes. Two distinct corrosion mechanisms were observed. For constant temperature conditions, the steel surface is covered by a silicate-rich layer, and corrosion rates were extremely low, indicating surface protection by CPs, and possibly by a stable barrier layer. When the steel surfaces experienced changes in temperature, metal surface appeared to be less smooth and eventually spatial separation of anodic and cathodic reactions occurred within two years. The consequence of this separation is that the local corrosion rate inside cavities (about $100 \mu \mathrm{m} / \mathrm{a}$ ) is about one order of magnitude greater than the average rate of corrosion (below $10 \mu \mathrm{m} / \mathrm{a}$ ).

The CPs observed in the present study compare in nature, if not in location, with the solids identified in the previous study [52]. Some solids that were specific to metal-replacing CPs, such as Fe silicate, now exclusively form near the original surface and in outer CPs. This is a possible consequence of alkaline $\mathrm{pH}$ and moderate $[\mathrm{Si}]_{\mathrm{aq}}$ conditions in the test chamber. The pervasive presence of magnetite away from the metal surface can also be noted. This finding indirectly supports previous modelling results for iron corrosion in clay media, which suggested the formation of magnetite layers away from metal, near the original surface [38]. This demonstrates that the models are actually reliable at predicting geochemical processes in the corrosion layers. It further supports the contention that the magnetite formation at the
metal-CPs interface [27-29] is not a geochemical process (i.e., it is not driven by solution equilibria), but rather an interfacial electrochemical process controlled by solid-state fluxes of reactants and charges [65].

The overall set of results obtained for MCO-Gravimetry coupons shows that localized corrosion, with spatially separated anodic and cathodic reactions, may occur in nuclear waste repository. The experience gained on clay-steel compact systems [27-29] however suggests that the occurrence of such galvanic coupling is hindered by nearneutral/alkaline $\mathrm{pH}$ values and by the presence of compact diffusion barriers at the steel surface. Areas of localized corrosion would spread out laterally, gradually covering the entire surface and resulting in transition to generalized corrosion. Alternatively, occurrence of cathodic reactions on cementite particles would keep spatial separation between anodic and cathodic reactions, delaying long-term passivation of the interface.

\section{Acknowledgments}

The authors want to thank Ph. Dillmann, M. Saheb, D. Neff, Y. Leon and D. Féron (CEA) and D. Crusset, N. Michau, and S. Schumacher (Andra) for fruitful discussions. This work was supported by The French National Agency for Nuclear Waste Management (Andra) and Electricité de France (EDF) within the GL Verre-Fer-Argile framework.

\section{References}

[1] G. De Marsily, E. Ledoux, A. Barbreau, J. Margat, Nuclear waste disposal: can the geologist guarantee isolation? Science 197 (1977) 519-527.

[2] K.B. Krauskopf, Aqueous geochemistry of radioactive waste disposal, Appl. Geochem. 1 (1986) 15-23.

[3] M. Sawiki, Council Directive 2011/70/EURATOM of 19 July 2011 establishing a community framework for the responsible and safe management of spent fuel and radioactive waste, Off. J. Eur. Union 199 (2011) 48-56.

[4] D. Féron, D. Crusset, J.M. Gras, Corrosion issues in nuclear waste disposal, J. Nucl. Mater. 379 (2008) 16-23.

[5] Andra, Evaluation de la faisabilité du stockage géologique en formation argileuse, Andra, Chatenay-Malabry, France, 2005.

[6] F. King, Overview of a carbon steel container corrosion model for a deep geological repository in sedimentary rock, in: NWMO-TR-2007-01 (Ed.), 2007.

[7] S. Tricoit, Modélisation et simulation numérique de la propagation de la corrosion par piqûres du fer en milieu chloruré: contribution à l'évaluation de la durabilité des aciers au carbone en conditions de stockage géologique, Ph.D. Thesis, University of Dijon, France, 2012.

[8] F. King, Waste containers, in: T.R. Allen, R.E. Stoller, S. Yamanaka (Eds.), Material Performance and Corrosion Waste Materials, Elsevier, Amsterdam, 2012, pp. $421-450$.

[9] J.-M. Gras, Life prediction for HLW containers - issues related to long-term extrapolation of corrosion resistance, C.R. Phys. 3 (2002) 891-902.

[10] F. Foct, J.M. Gras, Semi-empirical model for carbon steel corrosion in long term geological nuclear waste disposal, International Workshop Prediction of Long Term Corrosion Behaviour in Nuclear Waste Systems, EFC, Cadarache, France, 2002.

[11] J.-L. Crolet, N. Thevenot, S. Nesic, Role of conductive corrosion products in the protectiveness of corrosion layers, Corrosion 54 (1998) 194-202.

[12] M.B. Kermani, A. Morshed, Carbon dioxide corrosion in oil and gas production - a compendium, Corrosion 59 (2003) 659-683.

[13] A. Romaine, R. Sabot, M. Jeannin, S. Necib, P. Refait, Electrochemical synthesis and characterization of corrosion products on carbon steel under argillite layers in carbonated media at $80^{\circ} \mathrm{C}$, Electrochim. Acta 114 (2013) 152-158.

[14] A. Romaine, M. Jeannin, R. Sabot, S. Necib, P. Refait, Corrosion processes of carbon steel in argillite: galvanic effects associated with the heterogeneity of the corrosion product layer, Electrochim. Acta 182 (2015) 1019-1028.

[15] D. Charpentier, K. Devineau, R. Mosser-Ruck, M. Cathelineau, F. Villieras, Bentonite-iron interactions under alkaline condition: an experimental approach, Appl. Clay Sci. 32 (2006) 1-13.

[16] S. Savoye, L. Legrand, G. Sagon, S. Lecomte, A. Chaussé, R. Messina, P. Toulhoat, Experimental investigations on iron corrosion products formed in bicarbonate/ carbonate containing solutions at $90^{\circ} \mathrm{C}$, Corros. Sci. 43 (2001) 2049-2064.

[17] B. Lanson, S. Lantenois, P.A. van Aken, A. Bauer, A. Plancon, Experimental investigation of smectite interaction with metal iron at $80^{\circ} \mathrm{C}$ : structural characterization of newly formed Fe-rich phyllosilicates, Am. Miner. 97 (2012) 864-871.

[18] M. Perronnet, M. Jullien, F. Villieras, J. Raynal, D. Bonnin, G. Bruno, Evidence of a critical content in $\mathrm{Fe}(0)$ on FoCa7 bentonite reactivity at $80^{\circ} \mathrm{C}$, Appl. Clay Sci. 38 (2008) 187-202.

[19] I. Pignatelli, F. Bourdelle, D. Bartier, R. Mosser-Ruck, L. Truche, E. Mugnaioli, N. Michau, Iron-clay interactions: detailed study of the mineralogical transformation of claystone with emphasis on the formation of iron-rich T-O phyllosilicates in a step-by-step cooling experiment from $90^{\circ} \mathrm{C}$ to $40{ }^{\circ} \mathrm{C}$, Chem. Geol. 387 (2014) 1-11. 
[20] P. Le Pape, C. Rivard, M. Pelletier, I. Bihannic, R. Gley, S. Mathieu, L. Salsi, S. Migot, O. Barres, F. Villieras, N. Michau, Action of a clay suspension on an Fe(0) surface under anoxic conditions: characterization of neoformed minerals at the $\mathrm{Fe}$ (0)/solution and Fe(0)/atmosphere interfaces, Appl. Geochem. 61 (2015) 62-71.

[21] C. Rivard, E. Montarges-Pelletier, D. Vantelon, M. Pelletier, C. Karunakaran, L.J. Michot, F. Villieras, N. Michau, Combination of multi-scale and multi-edge Xray spectroscopy for investigating the products obtained from the interaction between kaolinite and metallic iron in anoxic conditions at $90^{\circ} \mathrm{C}$, Phys. Chem. Miner. 40 (2013) 115-132.

[22] C. Rivard, M. Pelletier, N. Michau, A. Razafitianamaharavo, I. Bihannic, M. Abdelmoula, J. Ghanbaja, F. Villieras, Berthierine-like mineral formation and stability during the interaction of kaolinite with metallic iron at $90{ }^{\circ} \mathrm{C}$ under anoxic and oxic conditions, Am. Miner. 98 (2013) 163-180.

[23] S. Kaufhold, A.W. Hassel, D. Sanders, R. Dohrmann, Corrosion of high-level radioactive waste iron-canisters in contact with bentonite, J. Hazard. Mater. 285 (2015) 464-473.

[24] L. Carlson, O. Karnland, V.M. Oversby, A.P. Rance, N.R. Smart, M. Snellman, M. Vahanen, L.O. Werme, Experimental studies of the interactions between anaerobically corroding iron and bentonite, Phys. Chem. Earth 32 (2007) 334-345.

[25] N.R. Smart, D.J. Blackwood, L. Werme, Anaerobic corrosion of carbon steel and cast iron in artificial groundwaters: part 1 - electrochemical aspects, Corrosion 58 (2002) 547-559.

[26] J. Stoulil, J. Kanok, M. Kouril, H. Parschova, P. Novak, Influence of temperature on corrosion rate and porosity of corrosion products of carbon steel in anoxic bentonite environment, J. Nucl. Mater. 443 (2013) 20-25.

[27] M.L. Schlegel, C. Bataillon, K. Benhamida, C. Blanc, D. Menut, J.-L. Lacour, Metal corrosion and argillite transformation at the water-saturated, high temperature iron-clay interface: a microscopic-scale study, Appl. Geochem. 23 (2008) 2619-2633.

[28] M.L. Schlegel, C. Bataillon, C. Blanc, D. Prêt, E. Foy, Anodic activation of iron corrosion in clay media under water-saturated conditions at $90{ }^{\circ} \mathrm{C}$ : characterization of the corrosion interface, Environ. Sci. Technol. 44 (2010) 1503-1508.

[29] M.L. Schlegel, C. Bataillon, F. Brucker, C. Blanc, D. Prêt, E. Foy, M. Chorro, Corrosion of metal iron in contact with anoxic clay at $90{ }^{\circ} \mathrm{C}$ : characterization of the corrosion products after two years of interaction, Appl. Geochem. 51 (2014) 1-14.

[30] J. Wilson, G. Cressey, B. Cressey, J. Cuadros, K.V. Ragnarsdottir, D. Savage, M. Shibata, The effect of iron on montmorillonite stability. (II) experimental investigation, Geochim. Cosmochim. Acta 70 (2006) 323-336.

[31] Y. El Mendili, A. Abdelouas, A.A. Chaou, J.F. Bardeau, M.L. Schlegel, Carbon steel corrosion in clay-rich environment, Corros. Sci. 88 (2014) 56-65.

[32] Y. El Mendili, A. Abdelouas, G. Karakurt, A.A. Chaou, R. Essehli, J.F. Bardeau, J.M. Greneche, The effect of temperature on carbon steel corrosion under geological conditions, Appl. Geochem. 52 (2015) 76-85.

[33] F.A. Martin, C. Bataillon, M.L. Schlegel, Corrosion of iron and low alloyed steel within a water saturated brick of clay under anaerobic deep geological disposal conditions: an integrated experiment, J. Nucl. Mater. 379 (2008) 80-90.

[34] D. Savage, C. Watson, S. Benbow, J. Wilson, Modelling iron-bentonite interactions, Appl. Clay Sci. 47 (2010) 91-98.

[35] F. King, M. Kolar, P.G. Keech, Simulations of long-term anaerobic corrosion of carbon steel containers in Canadian deep geological repository, Corr. Eng. Sci. Technol. 49 (2014) 455-459.

[36] J.C. Wilson, S. Benbow, H. Sasamoto, D. Savage, C. Watson, Thermodynamic and fully-coupled reactive transport models of a steel-bentonite interface, Appl. Geochem. 61 (2015) 10-28.

[37] O. Bildstein, L. Trotignon, M. Perronnet, M. Jullien, Modelling iron-clay interactions in deep geological disposal conditions, Phys. Chem. Earth 31 (2006) 618-625.

[38] O. Bildstein, J. -É. Lartigue, M.L. Schlegel, C. Bataillon, B. Cochepin, I. Isabelle Munier, N. Michau, Gaining insight into corrosion processes from numerical simulations of an integrated iron-claystone experiment, Clay Conference 2015, Geological Society Special Publication, Brussels, 2016.

[39] V.V. Ngo, A. Clément, N. Michau, B. Fritz, Kinetic modeling of interactions between iron, clay and water: comparison with data from batch experiments, Appl. Geochem. 53 (2015) 13-26.

[40] S. Réguer, D. Neff, L. Bellot-Gurlet, P. Dillmann, Deterioration of iron archaeological artefacts: micro-Raman investigation on $\mathrm{Cl}$-containing corrosion products, J. Raman Spectrosc. 38 (2007) 389-397.

[41] M. Saheb, M. Descostes, D. Neff, H. Matthiesen, A. Michelin, P. Dillmann, Iron corrosion in an anoxic soil: comparison between thermodynamic modelling and ferrous archaeological artefacts characterised along with the local in situ geochemical conditions, Appl. Geochem. 25 (2010) 1937-1948.

[42] M. Saheb, F. Marsal, H. Matthiesen, D. Neff, P. Dillmann, D. Pellegrini, Fluctuation of redox conditions in radioactive waste disposal cell: characterisation of corrosion layers formed on archaeological analogues, Corr. Eng. Sci. Technol. 46 (2011) 199-204.

[43] M. Saheb, D. Neff, J. Demory, E. Foy, P. Dillmann, Characterisation of corrosion layers formed on ferrous archaeological artefacts buried in anoxic media, Corr. Eng. Sci. Technol. 45 (2010) 381-387.

[44] M. Saheb, D. Neff, P. Dillmann, H. Matthiesen, E. Foy, Long-term corrosion behaviour of low-carbon steel in anoxic environment: characterization of archaeological artefacts, J. Nucl. Mater. 379 (2008) 118-123.

[45] D. Neff, M. Saheb, J. Monnier, S. Perrin, M. Descostes, V. L'Hostis, D. Crusset, A. Millard, P. Dillmann, A review of the archaeological analogue approaches to predict the long-term corrosion behaviour of carbon steel overpack and reinforced concrete structures in the French disposal systems, J. Nucl. Mater. 402 (2010) 196-205.

[46] D. Neff, E. Vega, P. Dillmann, M. Descostes, L. Bellot-Gurlet, G. Beranger,
Contribution of iron archeological artefacts to the estimation of average corrosion rates and the long-term corrosion mechanisms of low-carbon steel buried in soils, in: P. Dillmann, G. Beranger, P. Piccardo, H. Matthiesen (Eds.), Corrosion of Metallic Heritage Artefacts, 2007, pp. 41-76 (Woodhead, Cabridge, UK).

[47] P. Dillmann, D. Neff, D. Feron, Archaeological analogues and corrosion prediction: from past to future. A review, Corr. Eng. Sci. Technol. 49 (2014) 567-576.

[48] M. Saheb, D. Neff, P. Dillmann, M. Descostes, H. Matthiesen, Long-term anoxic corrosion of iron, in: P. Dillmann, D. Watkinson, E. Angelini, A. Adriaens (Eds.) Corrosion and Conservation of Cultural Heritage Metallic Artefacts, Woodhead Publishing, 2013, pp. 260-284.

[49] Y. Leon, M. Saheb, E. Drouet, D. Neff, E. Foy, E. Leroy, J.J. Dynes, P. Dillmann, Interfacial layer on archaeological mild steel corroded in carbonated anoxic environments studied with coupled micro and nano probes, Corros. Sci. 88 (2014) 23-35.

[50] A. Michelin, E. Leroy, D. Neff, J.J. Dynes, P. Dillmann, S. Gin, Archeological slag from Glinet: an example of silicate glass altered in an anoxic iron-rich environment, Chem. Geol. 413 (2015) 28-43.

[51] S. Necib, Y. Linard, D. Crusset, N. Michau, S. Daumas, E. Burger, A. Romaine, M.L. Schlegel, Corrosion at the carbon steel-clay borehole water and gas interfaces at $85^{\circ} \mathrm{C}$ under anoxic and transient acidic conditions, Corros. Sci. 111 (2016) 242-258.

[52] M.L. Schlegel, S. Necib, S. Daumas, C. Blanc, E. Foy, N. Trcera, A. Romaine, Microstructural characterization of carbon steel corrosion in clay borehole water, under anoxic and transient acidic conditions, Corros. Sci. 109 (2016) 126-144.

[53] J.A. Briones, W. Reichardt, Estimating microbial population counts by most probable number using microsoft excel (R), Microbiol. Methods 35 (1999) 157-161.

[54] A.P. Hammersley, FIT2D: a multi-purpose data reduction, analysis and visualization program, J. Appl. Cryst. 49 (2016) 646-652.

[55] A. Coudrain-Ribstein, P. Gouze, G. de Marsily, Temperature carbon dioxide partial pressure trends in confined aquifers, Chem. Geol. 145 (1998) 73-89.

[56] H. Venzlaff, D. Enning, J. Srinivasan, K.J.J. Mayrhofer, A.W. Hassel, F. Widdel, M. Stratmann, Accelerated cathodic reaction in microbial corrosion of iron due to direct electron uptake by sulfate-reducing bacteria, Corros. Sci. 66 (2013) 88-96.

[57] N. Güven, Smectites, in: S.W. Bailey (Ed.), Hydrous Phyllosilicates, Mineralogical Society of America, Washington, DC, 1988, pp. 497-559.

[58] S.W. Bailey, Structures and compositions of other trioctahedral 1:1 phyllosilicates, in: S.W. Bailey (Ed.), Hydrous Phyllosilicates, Mineralogical Society of America, Washington, DC, 1988, pp. 170-188.

[59] I. Pignatelli, E. Mugnaioli, J. Hybler, R. Mosser-Ruck, M. Cathelineau, N. Michau, A multi-step technique characterization of cronstedtite synthesized by iron-clay interaction in a step-by-step cooling procedure, Clays Clay Min. 61 (2013) 277-289.

[60] A. Elmaleh, S.C. Tarantino, M. Zema, B. Devouard, M. Fialin, The low-temperature magnetic signature of Fe-rich serpentine in CM2 chondrites: comparison with terrestrial cronstedtite and evolution with the degree of alteration, Geochem. Geophys. Geosyst. 13 (2012).

[61] A. Vinsot, M. Lundy, Y. Linard, S. Wechner, J. Trémosa, F. Claret, In situ characterisation of the Callovian-Oxfordian seepage water composition while exposing the rock to oxygen gas, Clays in Natural and Engineered Barriers for Radioactive Waste Confinement, (2015) Brussels.

[62] S. Grousset, Détermination De La Composition Isotopique Du Soufre Pour l'étude De l'origine, Biotique Ou Abiotique, Des Sulfures De Fer En Corrosion Anoxique, Ph.D Thesis, Chimie PArisTech, Paris, France, 2016.

[63] Y. Leon, P. Dillmann, D. Neff, M.L. Schlegel, E. Foy, J.J. Dynes, Interfacial layers at a nanometre scale on iron corroded in carbonated anoxic environments, RSC Adv. 7 (2017) 20101-20115.

[64] A. Michelin, E. Drouet, E. Foy, J.J. Dynes, D. Neff, P. Dillmann, Investigation at the nanometre scale on the corrosion mechanisms of archaeological ferrous artefacts by STXM, J. Anal. At. Spectrom. 28 (2013) 59-66.

[65] C. Bataillon, F. Bouchon, C. Chainais-Hillairet, C. Desgranges, E. Hoarau, F. Martin, S. Perrin, M. Tupin, J. Talandier, Corrosion modelling of iron based alloy in nuclear waste repository, Electrochim. Acta 55 (2010) 4451-4467.

[66] M. Saheb, D. Neff, C. Bataillon, E. Foy, P. Dillmann, Copper tracing to determine the micrometric electronic properties of a thick ferrous corrosion layer formed in an anoxic medium, Corros. Sci. 53 (2011) 2201-2207.

[67] D.W. Shoesmith, Assessing the corrosion performance of high-level nuclear waste containers, Corrosion 62 (2006) 703-722.

[68] J. Chen, Z. Qin, D.W. Shoesmith, Kinetics of corrosion film growth on copper in neutral chloride solutions containing small concentrations of sulfide, J. Electrochem. Soc. 157 (2010) C338-C345.

[69] J. Chen, Z. Qin, D.W. Shoesmith, Rate controlling reactions for copper corrosion in anaerobic aqueous sulphide solutions, Corr. Eng. Sci. Technol. 46 (2011) 138-141.

[70] B.W.A. Sherar, P.G. Keech, D.W. Shoesmith, Carbon steel corrosion under anaerobic-aerobic cycling conditions in near-neutral $\mathrm{pH}$ saline solutions - part 1: long term corrosion behaviour, Corros. Sci. 53 (2011) 3636-3642.

[71] P. Refait, A.M. Grolleau, M. Jeannin, E. Francois, R. Sabot, Localized corrosion of carbon steel in marine media: galvanic coupling and heterogeneity of the corrosion product layer, Corros. Sci. 111 (2016) 583-595.

[72] C. Remazeilles, D. Neff, F. Kergourlay, E. Foy, E. Conforto, E. Guilminot, S. Reguer, P. Refait, P. Dillmann, Mechanisms of long-term anaerobic corrosion of iron archaeological artefacts in seawater, Corros. Sci. 51 (2009) 2932-2941.

[73] S. Reguer, P. Dillmann, F. Mirambet, Buried iron archaeological artefacts: corrosion mechanisms related to the presence of Cl-containing phases, Corros. Sci. 49 (2007) 2726-2744.

[74] S. Reguer, P. Dillmann, F. Mirambet, L. Bellot-Gurlet, Local and structural characterisation of chlorinated phases formed on ferrous archaeological artefacts by (XRD and (XANES, Nucl. Instrum. Methods Phys. Res. B 240 (2005) 500-504. 
[75] C. Remazeilles, P. Refait, Formation, fast oxidation and thermodynamic data of Fe (II) hydroxychlorides, Corros. Sci. 50 (2008) 856-864.

[76] C.F. Pérez-Brokate, D. di Caprio, D. Féron, J. de Lamare, A. Chaussé, Three dimensional discrete stochastic model of occluded corrosion cell, Corros. Sci. 111 (2016) 230-241.

[77] S. Nešić, M. Nordsveen, R. Nyborg, A. Stangeland, A mechanistic model for carbon dioxide corrosion of mild steel in the presence of protective iron carbonate films part 2: a numerical experiment, Corrosion 59 (2003) 489-497.

[78] S. Nesic, Key issues related to modelling of internal corrosion of oil and gas pipelines - a review, Corros. Sci. 49 (2007) 4308-4338.

[79] M.B. Nemer, Y.L. Xiong, A.E. Ismail, J.H. Jang, Solubility of $\mathrm{Fe}_{2}(\mathrm{OH})_{3} \mathrm{Cl}$ (pure-iron end-member of hibbingite) in $\mathrm{NaCl}$ and $\mathrm{Na}_{2} \mathrm{SO}_{4}$ brines, Chem. Geol. 280 (2011) $26-32$.

[80] M. Pourbaix, Applications of electrochemistry in corrosion science and in practice, Corros. Sci. 14 (1974) 25-82.

[81] I. Azoulay, C. Remazeilles, P. Refait, Determination of standard Gibbs free energy of formation of chukanovite and Pourbaix diagrams of iron in carbonated media,
Corros. Sci. 58 (2012) 229-236.

[82] P.M. Dove, J.D. Rimstidt, Silica-water interactions, in: P.J. Heaney, C.T. Prewitt (Eds.), Silica: Physical Behavior, Geochemistry and Materials Application, Mineralogical Society of America, Washington, DC, 1994, pp. 259-308.

[83] F.H. Sweeton, R.E. Mesmer, C.F. Baes, Acidity measurements at elevated temperatures. VII. dissociation of water, J. Solut. Chem. 3 (1974) 191-214.

[84] J.T. Trevors, C.M. Cotter, Copper toxicity and uptake in microorganisms, J. Ind. Microbiol. 6 (1990) 77-84.

[85] S. Shakeri Yekta, A. Lindmark, U. Skyllberg, A. Danielsson, B.H. Svensson, Importance of reduced sulfur for the equilibrium chemistry and kinetics of $\mathrm{Fe}(\mathrm{II})$, $\mathrm{Co}$ (II) and Ni(II) supplemented to semi-continuous stirred tank biogas reactors fed with stillage, J. Hazard. Mater. 269 (2014) 83-88.

[86] D. Enning, H. Venzlaff, J. Garrelfs, H.T. Dinh, V. Meyer, K. Mayrhofer, A.W. Hassel, M. Stratmann, F. Widdel, Marine sulfate-reducing bacteria cause serious corrosion of iron under electroconductive biogenic mineral crust, Environ. Microbiol. 14 (2012) 1772-1787. 